\title{
LA IDENTIDAD MAGALLÁNICA DADOS LOS PRINCIPALES CAMBIOS ECONÓMICOS Y ESTRUCTURALES OCURRIDOS EN CHILE ENTRE 1960 Y 2008
}

SERGIO SOZA-AMIGO

\section{RESUMEN}

El presente trabajo consiste en identificar a la o las actividades económicas que han contribuido al desarrollo de la región de Magallanes, para ello se recurre a dos variables, al Producto Interno Bruto Regionalizado (PIBr) y Empleo por Rama de Actividad Económica (PEA). En este propósito, se consideran dos horizontes de tiempo, uno que va desde 1960 al año 2006 para la primera variable y, desde 1986 a 2008, para la segunda.

Los resultados, ayudan a establecer qué actividades económicas son las más representativas del funcionamiento productivo regional. De igual forma, se desprenden las repercusiones de posibles shock económicos que pueden acaecer en esta economía una vez que estos son implementados, ello en un escenario caeteris paribus.

Actualmente Magallanes en base a su PEA se identifica con ramas vinculadas a los servicios, mientras que el PIBr señala a la minería e industria manufacturera. Por otra parte, se aprecia que en Magallanes hay una tendencia a especializarse en actividades de rápido crecimiento regional, pero lentas a nivel nacional.

PALABRAS CLAVES: identidad regional, planificación, estructura económica, shift-share.

Universidad de Magallanes, Facultad de Ciencias Económicas y Jurídicas, Av. Bulnes 01855, Punta Arenas, Chile, e-mail: sergio.soza@umag.cl.

1 Este artículo forma parte del "Estudio para el Fortalecimiento de la Identidad Regional". Encargado y financiado por el Servicio Gobierno Regional de Magallanes y Antártica Chilena y ejecutado por la Universidad de Magallanes (Licitación privada 1609-11034-B208). Iniciativa de la Subsecretaría de Desarrollo Regional y Administrativo (SUBDERE) en conjunto con los Gobiernos Regionales.

2 Además se reconoce y agradece el apoyo del Núcleo de la Iniciativa Científica Milenio "Ciencia Regional y Políticas Públicas". 


\section{MAGELIAN IDENTITY GIVEN THE PRINCIPAL ECONOMIC AND STRUCTURAL CHANGES OCURRED IN CHILE BETWEEN 1960 AND 2008}

\section{ABSTRACT}

The present work consists in identifying the economic activity or activities that have contributed to the development of the Magellan region. For this we recognize two variables, the Internal Gross Product (PIBr) and Employment by Branch of Economic Activity (PEA). In this intention, we consider two time horizons, one from 1960 to year 2006 for the first variable and, from 1986 to 2008, for the second.

Results help us establish the most representative economic activities in the functioning regional production. Also, some repercussions are advanced in relation to a possible economic shock, which in this economy can happen as soon as these are implemented, in a caeteris paribus scene.

Nowadays the Magellan region, on the basis of its PEA, is identified with branches linked to services, where as the PIBr focuses on mining and manufacturing industry. On the other hand, we perceive that Magellan has specialized itself in activities of rapid regional growth, but slow in a national level.

KEYWORDS: regional identity, planning, economic structure, shift-share.

\section{INTRODUCCIÓN}

Una de las grandes dificultadas a las que se enfrenta el planificador regional, es el tener que disponer de herramientas e instrumentos que le faciliten la toma de decisiones; en este sentido, en general, cuando se analiza una economía se suele comenzar con la pregunta, de dónde se viene o, qué es lo que más identifica una localidad, con la intención de averiguar qué, es lo que ha sostenido o identificado al menos en términos económicos a una región. $\mathrm{O}$ bien, surgen cuestionamientos sobre qué áreas intervenir, en cuáles invertir o, dónde plantear determinadas políticas económicas, a fin de obtener un crecimiento específico que debiera inducir a un desarrollo económico, ya sea local o nacional.

En respuesta a lo anterior, se presenta un trabajo que se basa en la aplicación del modelo shift- share (clásico). Este modelo puede ayudar a establecer ciertas condiciones mínimas que facilitarían el comprender la identidad y planificación de la economía magallánica, ya que el modelo se basa en una serie de indicadores que responden a la estructura de una economía y a cómo ésta se ve afectada, dado los vaivenes que enfrente el que se considere patrón de referencia, que para el caso materia de estudio es Chile.
Del citado modelo se encuentran respuestas tales como, dónde está concentrada la actividad productiva de una nación y región, qué sector es el más preponderante en éstas, cuál es el multiplicar de empleo, esto es, qué se puede esperar, en términos de generación o pérdida de empleo sí, se genera un cierto cambio en una actividad, qué ocurre sí, en la base económica de una localidad se genera un empleo más en forma directa, ¿tiene repercusiones indirectas?. Más otros cuestionamientos que ayudan a determinar entre otras cosas el origen y destino en términos de participación de las variables analizadas.

Resumiendo, se aplicará una metodología que utilizando como indicador el empleo por rama de actividad económica (PEA) y el producto interno bruto regionalizado $(\mathrm{PIBr})$, primero mostrará la estructura económica de la región de Magallanes, desprendiéndose de allí, por ejemplo; el grado de especialización que sus actividades manifiestan, además de identificar el aporte de cada sector a la región, esto es, en términos de empleo y producto y, en segundo lugar, se cuantificará qué puede ocurrir en un determinado sector frente a posibles cambios macroeconómicos, es decir, primero se mide la evolución histórica de la economía, comparando las variables antes mencionadas y, en segundo lugar y, como un complemento para la primera parte, se 
intenta predecir, lo que se podría esperar a futuro -caeteris paribus-, considerando las variables que son propias de una economía y que en este caso son utilizadas.

Entendiendo el por qué de la importancia de la identidad y su relación con la "planificación estratégica"

Antes de comenzar un proceso de inversión, es menester definir para el contexto en que se trabajará qué es la "planificación estratégica".

En respuesta a la pregunta anterior, se debe comenzar por revisar lo que se entiende por el concepto "planificación estratégica", una definición global que se podría dar de ella es proceso en el cual, cada empresa (o, en este caso región), orienta sus actividades, en pos de lograr una mayor rentabilidad (en el caso de una localidad, desarrollo económico), para lo cual, considera la relación que existe entre ella y su entorno. Este proceso a su vez, debe permitir que las metas a lograr permitan satisfacer lo más posible el gran objetivo final. Para lograr esto último, se fijan umbrales específicos que deberán poseer una cierta flexibilidad frente a los posibles cambios que pudieran ocurrir en el mercado o economía, razón por la cual, además, se deben revisar con frecuencia, midiendo el grado de éxitos o fracasos logrados, estableciendo así -casi automáticamente-, un proceso iterativo, o si se prefiere cíclico, que permita reorientar los esfuerzos en pro de lograr la meta establecida.

Lo anterior es una definición de lo que se puede llegar a entender por planificación estratégica, pues, logra aglutinar la opinión de los siguientes autores: Lambin (1991), Porter (1991a), Hax y Majluf (1993), MIDEPLAN (1994) y Suárez (1994).

Como se comienza a vislumbrar, entre la planificación e identidad se establece una suerte de simbiosis. El planificar o, el establecer un proceso de planificación ${ }^{3}$, es importante, pues, da las bases para concretar un proceso que se inicia con la identificación de las características propias de cada región, esto es, una vez que se ha definido "lo que ha sido una región", es decir, se ha caracterizado un área con una "identidad, en este caso económica", a

3 El que se entiende por, mantener viva la planificación, ya que esta no termina, siempre está bajo constantes revisiones y modificaciones, lo que se debe hacer en forma estratégica. la planificación le corresponderá indicar lo que será y como ello se logrará. Por tanto, surge en primera instancia, la real necesidad de saber qué motiva y mantiene viva a una región, desde la perspectiva de la economía.

En términos generales, algunos de los beneficios que se pueden lograr con una adecuada identificación y planificación, son:

1. Secuencia lógica de los pasos a dar, para lograr un macro objetivo, facilitando así la correcta toma de decisiones.

2. El permitir una rápida y oportuna toma de decisiones, frente a los posibles cambios repentinos que se puedan presentar en el escenario en el cual está inserta una región.

3. En general, facilita una mejor administración de los recursos.

4. Aumenta la eficiencia productiva que se traduce en una liberación de recursos.

5. En muchos aspectos, produce mejoras sustanciales en el manejo de los recursos, pues permite un ahorro de estos, los que pueden ser traspasados a políticas de índole social.

En base a los argumentos recién esgrimidos, los cuales dan prueba de lo importante que es para un proceso de planificación, el desarrollar un adecuado diagnóstico, es decir, lo que ha sido una región, esto es, definir su identidad en al menos ciertas datas concretas $y$, por otra parte, de lo que de él también se desprenda pueda llegar ser, el trabajo realizado da luz sobre los principales cambios estructurales que han estado presentes en el periodo 1960-2008. A partir de estos se analiza cuáles eran o son las actividades precursoras de desarrollo en Magallanes, y a partir de los ciclos económicos que se forman en este periodo, se realiza un estudio que permite identificar las particularidades y potencialidades de la región materia de estudio.

\section{HIPÓTESIS}

La estructura económica de Magallanes, caracterizada en base a la población económicamente activa y producto interno bruto regionalizado para determinados ciclos económicos, identifica a la región y manifiesta qué ramas son más importantes para el desarrollo local. 


\section{OBJETIVO GENERAL}

Identificar las actividades más importantes de la estructura económica de la región de Magallanes, haciendo uso del modelo shift- share (clásico).

\section{MATERIALES Y MÉTODOS}

\section{Modelo Shift- Share}

La creación de este modelo, se fundamenta en la economía industrial y se utiliza con mucho éxito en la planificación regional. Tal uso, obedecería a la interpretación de sus respuestas, en este sentido, ellas facilitan el realizar un diagnóstico cuantitativo y cualitativo de la estructura económica regional que se analice ocupando un único dato de entrada, el que puede ser, por ejemplo; la Población Económicamente Activa por Rama de Actividad Económica (PEA), el Producto Interno Bruto Regionalizado (PIBr), las exportaciones, el ingreso, inversión, etc ${ }^{4}$.

La gran particularidad y ventaja que este modelo tiene, es el fácil acceso a datos o indicadores que requiere para su utilización (S. Boisier, 1980). Además, entrega una visión más clara de los efectos o repercusiones económicas que pueden ocurrir, en respuesta a una cierta medida local o externa (L. Lira, et al, 1993).

Como se aprecia, la técnica a utilizar es una herramienta estadística que facilita el entendimiento del desarrollo de una economía regional inserta en una nacional, en este sentido, según Mayor y López (pp. 2, 2005) de ella se puede desprender el análisis de dos factores; por un lado, aquel que presta atención a factores que operen sobre el territorio analizado de manera más o menos uniforme. En esta línea, su impacto estará en función

4 Para una mejor comprensión de la forma en que se determina cada indicador, su significado, así como el de las variables empleadas ver: Boisier, Sergio. 1980. Técnicas de análisis regional con información limitada. Instituto Latinoamericano y del Caribe de Planificación Económica y Social, ILPES, Santiago, Chile; Haddad, P., Carvalho Ferreira, C., y otros. 1989. Economia Regional: teorias e métodos de analise. Banco do Nordeste do Brasil. Brasil: Fortaleza; y principalmente en Lira, L., y V. Silva. 1993. Técnicas de análisis regional: ejercitación y aplicación. Instituto Latinoamericano y del Caribe de Planificación Económica y Social, ILPES, Santiago, Chile. de la disposición que presente la producción de cada región $y$, por otro, se aborda un componente más específico y opera en las regiones, esto es, la especialización de cada una.

\section{Elección del indicador}

Usualmente, cuando se utiliza este modelo en planificación regional, se recomienda en su uso el empleo de datos de entrada tales como la PEA por rama de actividad económica para lograr una mayor eficiencia. Luego, el salario real por rama de actividad económica, el PGBr (Producto geográfico Bruto regionalizado) o PIBr (L. Lira et al, 1993; S. Boisier, 1980; Ch. Tiebout 1972; y H. Nourse, 1968).

Dado que se quiere establecer cuál ha sido para determinados instantes la estructura económica de la región materia de estudio, considerando un horizonte de tiempo amplio, adicionalmente, se desea que el estudio contemple la situación en que se encontraba Magallanes cuando es el país el que presenta cambios estructurales y, también se espera que los resultados obtenidos se pueden utilizar para incrementar la población económicamente activa, se considera que las variables a emplear más adecuadas en base a la información disponible y los fines perseguidos son, la PEA por rama de actividad económica y el PIBr. La elección de éstas, obedece a las claras ventajas que ellas ofrecen para la aplicación de futuras medidas de carácter político económico, pues de tal análisis se podrá derivar, por ejemplo, cuáles son los efectos multiplicadores de determinadas actividades o, lo concentrada que está una rama en una región o, lo importante que es una actividad para el país (el cual es tomado como patrón de referencia). Con esto, no se pretende excluir del análisis las ventajas competitivas de cada región si no, por el contrario, acentuarlas vía localización y especialización. De igual forma, se eligen estas dos variables, dado que se asume "el empleo origina el principal de ingreso de la población", por otra parte, el uso del PIBr, obedece a un mecanismo de validación de la variable que se toma como base.

Lo anterior, responde a la información implícita que trae el PIBr, o visto desde otra perspectiva, dada a una de las formas en que puede ser determinado. Un método para fijar su valor es vía suma de todos los valores añadidos (VA), los cuales están compuestos entre otros por: remuneraciones, cier- 
Tabla 1. Composición Porcentual del Empleo y PIBr por Rama de Actividad en Magallanes.

\begin{tabular}{|r|r|r|r|r|r|r|r|r|}
\hline \multirow{2}{*}{ Año/ Rama } & \multicolumn{2}{|c|}{2003} & \multicolumn{2}{|c|}{2004} & \multicolumn{2}{|c|}{2005} & \multicolumn{2}{c|}{2006} \\
\cline { 2 - 8 } & Empleo & PIBr & Empleo & PIBr & Empleo & \multicolumn{1}{c|}{$\mathrm{PIBr}$} & Empleo & \multicolumn{1}{c|}{ PIBr } \\
\hline A- S- C y P & 10,65 & 5,28 & 9,91 & 5,54 & 8,26 & 5,64 & 10,95 & 5,53 \\
Minas & 3,82 & 9,23 & 1,44 & 9,27 & 4,83 & 8,47 & 4,66 & 8,15 \\
Industria & 9,98 & 17,94 & 12,92 & 18,17 & 10,36 & 18,31 & 8,57 & 18,24 \\
E-G-A & 0,75 & 3,12 & 1,17 & 3,04 & 0,64 & 2,98 & 1,51 & 3,08 \\
Construcción & 9,69 & 7,54 & 9,50 & 7,37 & 8,51 & 7,72 & 10,80 & 7,70 \\
Comercio & 18,99 & 10,58 & 18,72 & 10,74 & 18,22 & 11,09 & 17,01 & 11,39 \\
Ty C & 9,34 & 10,06 & 8,76 & 10,05 & 11,85 & 10,22 & 10,98 & 10,46 \\
S. Financieros & 4,81 & 22,71 & 6,22 & 22,86 & 7,10 & 23,28 & 5,43 & 23,50 \\
Ss. Cc. y Ss. & 31,97 & 13,54 & 31,35 & 12,96 & 30,24 & 12,30 & 30,10 & 11,95 \\
Total & 100 & 100 & 100 & 100 & 100 & 100 & 100 \\
\hline
\end{tabular}

Fuente: Propia en base a Banco Central e INE de Chile.

tos impuestos y el excedente bruto de explotación. Dado que esta última variable es la que guarda directa relación con las utilidades de la actividad, es la que hace precisamente que su empleo pierda objetividad o, se dificulte la focalización de ciertas políticas económicas, aún cuando, se establezcan ciertas condiciones impositivas.

Por otra parte, si se hace una lectura simultánea de las variables empleo y $\mathrm{PIBr}$ para el caso que nos ocupa (tabla 1), se observa que la incidencia efectiva que tiene cada rama en la actividad local es poco clara, esto es, por ejemplo, la rama que más empleo albergó en 2003 fue la de servicios comunales y sociales (Ss. Cc. y Ss.; 31.97\%), sin embargo, si se ve su aporte en términos de $\mathrm{PIBr}$, ocupa el tercer lugar (13.54\%), un caso más incierto aún es el observado en el sector servicios financieros en 2006, basado en la variable PIBr, fue la que más aportó (23.5\%), pero en términos de empleos es una de las que menos participación presentó (5.43\%), en concreto es la tercera con menor importancia, situación similar se observa en ese mismo año para la rama industria, en base a su $\mathrm{PIBr}$, es la segunda en relevancia (18.24\%), pero en empleo esta no genera grandes aportes (8.57\%).

Situaciones como las descritas -y sin considerar el daño que genera la agregación de datos, dejan de manifiesto que el empleo de la variable PIBr no es recomendado, al menos, cuando los objetivos son como los aquí trazados, pues si la meta es el incremento del $\mathrm{PIBr}$-variable cuestionada, a no ser que exista una distribución más homogénea entre salarios y excedente bruto de explotación-, entonces se debe emplear tal macro magnitud en esta clase de estudios.

Para comprender lo anterior, tómese como ejemplo, la aplicación de una política económica que esté destinada a un mayor aumento del empleo o incremento en los salarios, si se hace uso de la variable PIBr y aplica el modelo (shift- share), no se garantiza que su impacto satisfaga el objetivo impuesto, sino que puede ocurrir que tal medida tienda a favorecer al excedente bruto de explotación -producto de la agregación empleada y, lo que representa el PIBr-, como se ve, el empleo de tal variable dificulta el conocimiento en detalle de, por ejemplo, cuanto de la implementación afectará a los salarios y cuanto a excedente bruto de explotación.

Lo anterior, se acrecienta si se agrega la existencia de sectores en donde la relación excedente/ salarios es muy alta -mucha utilidad y bajos salarios-, un ejemplo, sobre este particular, se da en ramas tales como la acuicultura, en algunos procesos de la industria manufacturera $y$, en algunos tipos de turismo. Bajo tales condiciones, la aplicación de políticas económicas orientadas a buscar una mejora para la población, vía incremento salarial, suele dificultarse o el cumplimiento de los objetivos perderse, ya que efectivamente puede que se incrementa el PIBr, pero no se sabe en detalle qué parte de sus componentes lo hacen más, una circunstancia que de cierto modo ayuda a comprender y explicar este punto, es el que aún perduren problemas de redistribución de la riqueza (el 20\% de la población recibe el 80\% de ella).

Si bien es cierto, y según se desprende del 
párrafo precedente, se hace atractivo el uso de los salarios por rama de actividad como variable base, a objeto de incrementar, por ejemplo, el bienestar. El empleo de la PEA no es errado, puesto que se responde a otro tipo de objetivos, a saber, el establecer los efectos directos e indirectos en, por ejemplo, un determinado sector en donde se ha incrementado el empleo. Por otra parte, al carecer de la información relativa a los salarios reales por región y sector para todo el horizonte de tiempo considerado o, el disponer de ella pero para una data que no coincide con los cambios estructurales que presenta la economía chilena -recordar que esta información existe en los CENSOS-, su uso se hace poco atractivo, ya que lo importante es saber en qué condiciones se encontraba la economía -en este caso, magallánica-, cuando han ocurrido cambios estructurales en la economía que se toma como patrón de referencia.

\section{La data a considerar para el análisis dinámico}

En relación a este punto, la elección del período de tiempo a considerar en la aplicación de la metodología shift- share es un aspecto a meditar y razonar, si bien es cierto existe consenso en cuanto a que el mismo debe ser amplio y variado, esto es, en general, en periodos de 10 años -espacio que corresponde históricamente a la toma de CENSOS-, no lo existe, respecto a la consideración de otros inter períodos que en particular resultan ser interesantes de analizar - de año en año, cada 3 años, de 5 en cinco, etc-, mientras por un lado existen investigadores que se decantan por elegir a priori un par de años y evaluar la dinámica de la economía que se analiza, por ejemplo entre CENSOS o, bien, cada dos años -lo que depende de los datos utilizados-, el suscrito sugiere optar por un criterio que sea más práctico, esto es, que considere los momentos en los cuales la economía nacional ha sido presa de cambios estructurales importantes. La razón de tal sugerencia obedece al hecho de que es en ese instante cuando se aprecian con más detalle qué actividades económicas "locales" están más acorde a los cambios que experimenta la nación, esto es, saber cuáles son las actividades que le dan dinamismo a la economía nacional y cuáles están algo más rezagadas con el objeto de encaminar la economía local con la nacional. Este aspecto es importante pues, los cambios estructurales generalmente responden a las consecuencias imperantes en los mercados externos, o bien, a las políticas económicas trazadas a nivel global por la Autoridad Nacional y no por la Local. En este sentido, una alternativa puede ser el partir por definir en base a los cambios estructurales que ha experimentado el empleo en la economía nacional y el PIBr, cuáles serán los instantes de evaluación y, a partir de estos, observar qué ramas para esos instantes son las más importantes tanto en el contexto nacional como para la economía que se estudia. Es decir, una alternativa a considerar es aplicar la técnica shift- share (clásica), en base a, primero, los cambios estructurales que se observan en Chile para la variable empleo y, en segundo lugar, en base al PIBr, como una forma de validar las distintas interpretaciones.

En consonancia con lo anterior, existe otro aspecto a evaluar; él tendría que ver con los cambios estructurales que se observan, dependiendo del uso de cada variable, esto es, qué criterio aplicar sí, los cambios estructurales detectados por la PEA, no coinciden con los del PIBr. Dado que, en este caso, la idea es analizar cambios que puedan tener a futuro alguna utilidad en, digamos una cierta política económica destinada a fomentar el empleo, lo que se propone es analizar la dinámica económica para el período de tiempo que se considere, adecuando en base a la variable empleo. Una vez realizado ello, se sugiere constatar sí tal dinámica económica es coincidente con la que se obtiene utilizando el PIBr. Si ocurre que para ambas variables los cambios estructurales no coinciden, se deben validar los resultados preliminares vía un análisis dinámico para el período que se desprende de la variable empleo pero, con la variable $\mathrm{PIBr}$, es decir, de no coincidir los períodos, se sugiere realizar un análisis shift- share (clásico), con las variables PEA y PIBr, en base a los cambios estructurales que se detecten con el empleo.

Por otra parte, se deja constancia que, aún cuando los cambios estructurales también se analizan vía PIBr, en este caso dicho estudio se omite, dado los argumentos esgrimidos con anterioridad y, que guardan relación con la información implícita que trae tal variable y los objetivos aquí perseguidos, esto es, el definir en cuanto podría aumentar el empleo en Magallanes dadas determinadas condiciones. 
Ventajas y desventajas del modelo aplicado

Entre las ventajas de la técnica shift-share (clásica) está la consideración de la evolución en el tiempo de la variable que se utiliza, esto es, evaluar las repercusiones que tiene la modificación de su magnitud en dos instantes de tiempo, a partir de los cuales, se establecen los efectos nacionales, sectoriales y competitivo.

Por su parte, algunas de sus desventajas son, la ausencia de la interrelación geográfica entre regiones, esto es, aún cuando la técnica captura algunas actividades con carácter asociativo, no incluye la consideración de la vecindad entre las regiones analizadas; de esta forma sus resultados se limitan a las diferencias y similitudes estructurales que existen entre las regiones respecto a un patrón de referencia el cual, generalmente, es el país. Es decir, la técnica no considera la influencia de la variable espacio en sus indicadores, esto es, no captura la interacción espacial entre regiones o, en palabras de Hewings (1976), no manifiesta en forma explícita la interacción entre las regiones que se analizan. En esta misma línea, existe otro aspecto que no considera la técnica y es la repercusión que tiene la variación de digamos la i-ésima actividad realizada en la r-ésima región en la n-ésima localidad. En esta misma línea, Dinc et al (1998), señala que, aún cuando se incorpore este aspecto al estudio, esto es, la inclusión de la interacción espacial, surge tras ello el problema de las dependencias entre sectores y regiones pero en esta ocasión para el contexto espacial, lo cual dificulta el análisis, en este sentido, como se puede dilucidar corresponderá al analista considerar la pertinencia de la inclusión o exclusión de tal aspecto, el que tendrá como base de decisión, las características geográficas de la nación que se estudie.

Lo anterior, es un aspecto no menor, pues la técnica puede entrar en conflicto con los objetivos trazados por el analista, si ellos son, por ejemplo, el averiguar qué competitiva es una región respecto a su contorno geográfico inmediato. El análisis se dificulta dado que la técnica no permite cuantificar la dependencia espacial que existe entre la región que se analiza con su entorno, esto es, se dificulta el saber si la actividad localizada en la r-ésima región es competitiva producto de su vecindad con la n-ésima, o bien, tal cambio es producto de una evolución propia del sector en la región, en respuesta a una externalidad o motivación cuyo origen es distinto de la interacción propia que pueda tener con la n-ésima región (Mayor, 2005a y 2005b).

\section{La consideración del espacio \\ geográfico en la aplicación}

Aún cuando se pueda dar solución al escollo que se detecta en relación con el "problema espacial", lo que sería originado por el supuesto de que las regiones se ven como casos aislados, esto es, las economías que la rodean no tienen ingerencia en el desarrollo de las localidades próximas. El incorporar dicho aspecto, trae consigo otros problemas como, por ejemplo, el incremento en las relaciones entre espacios y sectores, lo que origina una profusión tal de nuevas interpretaciones que, en vez de facilitar el estudio lo dificultan (Dinc et al, 1998).

Independientemente de lo anterior, si se asumiese que una región tiene un cierto intercambio con sus economías vecinas, la solución pasaría por incorporar en el estudio una matriz de pesos espaciales, en donde se capture este incremento de relaciones de intercambio, por ejemplo, mediante las técnicas de Moran (1948), Geary (1954), Fingleton (2001) o de Nazara y Hewings (2004). El problema en ello, es que para el caso estudio, y en general, para el contexto chileno, se tiene por un lado que, el gran intercambio entre regiones se da sólo con la zona Metropolitana y no entre regiones vecinas. Acto seguido, se debe sumar la continuidad longitudinal que presenta la geografía del país. Por otra parte, el caso de Magallanes, corresponde al de una zona extrema, que no tiene un intercambio de actividades significativo con otras regiones (exceptuando la metropolitana) e, incluyendo en forma mínima a la de Aysén, pero además ocurre que presenta un cierto flujo comercial con el área vinculada a la Provincia de Santa Cruz, Argentina. Con respecto a este punto, aún cuando se quiera dar solución a ello, esto es, si esta Provincia se incorporase al análisis, se presenta el problema de que tal zona no tiene mayor intercambio con el resto del territorio nacional, luego su inclusión más que ser práctica dificulta el obtener conclusiones y trae entre otras consecuencias que, estas localidades se traten como zonas aisladas, esto es, se induce a trabajar fuera del contexto nacional, lo que para los fines de este trabajo, no es recomendado, ya 


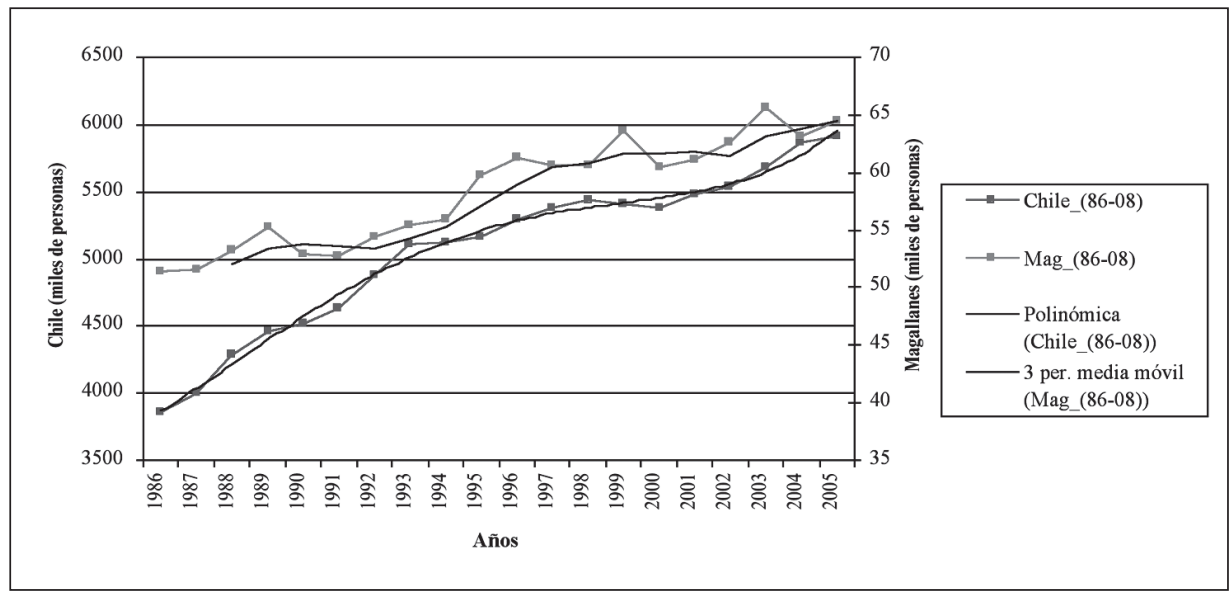

Fig. 1. Empleo para Chile y Magallanes periodo 1986- 2005. Fuente: Propia en base a INE.

que Magallanes depende de las políticas nacionales chilenas. Por otra parte, el intercambio entre estas zonas, obedece más bien a un intercambio del sector comercio o, de actividades vinculadas al turismo y no de, por ejemplo, la industria manufacturera o actividades que requieran un alto intercambio de insumos o servicios.

\section{RESULTADOS}

Revisión preliminar de las variables que serán empleadas

Como etapa previa a la aplicación de la técnica shift- share (clásico), se procede a revisar cuál ha sido el comportamiento de la variable empleo por rama de actividad económica desde el año 1986 a 2008 , ello tanto para el contexto nacional como magallánico (Fig. 1, nótese que en el sólo se señala el periodo 1986-2005, los años 2006 a 2008, son incluidos en el Fig. 2).

De la Fig. 1, se pueden observar algunos aspectos interesantes. Por ejemplo, la forma que toma la tendencia del empleo total en Magallanes respecto a lo que ocurre en el contexto nacional, cómo se aprecia, si se traza una media móvil para el empleo total en Chile, se obtiene una alta coincidencia con la línea de tendencia regional hasta el año 2005 , esto se puede interpretar como, dado los cambios ocurridos en la variable empleo (nacional), dichas alteraciones se manifiestan en Magallanes en un periodo próximo a los tres (3) años.
En base a lo comentado, se hace notar que las tendencias de estas repercusiones sólo son validas para este ciclo, ya que cuando se aumenta la serie hasta el año 2008 (Fig. 2), dicha propensión cambia dada la disminución que se produce en el empleo magallánico, situación que en el corto plazo debiese revertirse, ya que los sectores afectados con la excepción de minas y canteras corresponden a distintos servicios. Ocurrido esto último, las curvas tomarían nuevamente las tendencias presentadas hasta el año 2005, retomando por tanto las consecuencias ya señaladas.

De igual forma se aprecia que en Magallanes han existido episodios en donde hay incrementos en el empleo; por ejemplo en los años 1988; 1989; 1992; 1995; 1996; 1999; 2002 y 2003, de estos los más importantes han sido los ocurridos en 1995 con un 7\% y, en 1999 y 2003 con un 5\%.

Con respecto a lo ocurrido en 1995 , dicho incremento (siete por ciento), se debería al incremento del $51 \%$ experimentado en el sector financiero, un $45 \%$ en el de comercio, un $24 \%$ en el sector minero y un $12 \%$ en transporte y comunicaciones (Fig. 2).

Por su parte, el incremento experimentado en 1999 respecto al año anterior, obedecería a los cambios acaecidos en industria manufacturera (un 54\%), seguido en menor cantidad por servicios financieros, transporte y comunicaciones y agricultura, silvicultura, ganadería y pesca con 15; 10 y $7 \%$ respectivamente.

Finalmente, los cambios que se vislumbran para el año 2003 respecto al 2002, se justificarían 


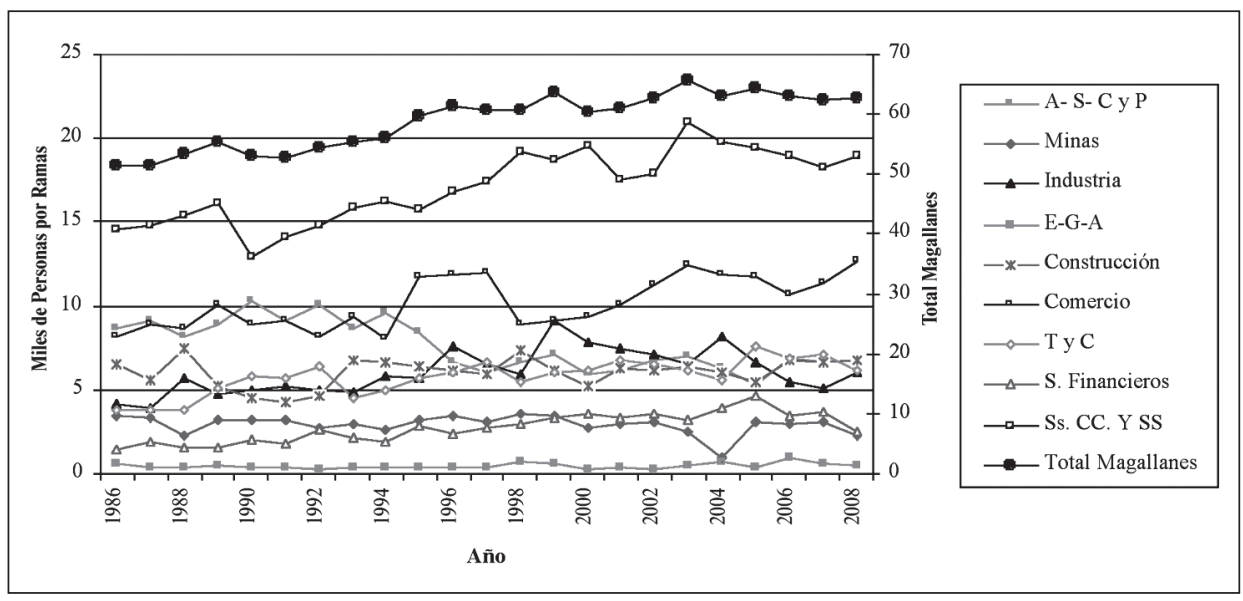

Fig. 2. Empleo por ramas económicas en Magallanes periodo 1986- $2008^{3}$.

Fuente: INE.

por incrementos en ramas tales como, electricidad, gas y agua, servicios comunales y sociales, comercio y construcción, con 104; $17 ; 11$ y 4\% respectivamente.

De la Fig. 2, también se observa que ramas son las que históricamente para el periodo considerado concentran el empleo en la región magallánica, esto es, de acuerdo a lo observado la región basa su economía en los servicios comunales y sociales (servicios públicos y otros), comercio y, en parte en industria manufactura (esto debe ser visto con precaución pues, se observa una tendencia a la baja en este rubro). De igual forma se vislumbra que para los últimos años existe un leve incremento en las ramas de transporte y comunicaciones y de servicios financieros.

En referencia a los cambios en importancia que ha presentado el empleo, se observa que para los primeros años, actividades tales como, construcción, guardaban cierta relevancia, sin embargo, al llegar al año 2000, esta fue perdiendo importancia en términos de volumen, situación similar ocurriría con agricultura, silvicultura, caza y pesca (A- S- C y P), para los primeros años estos sectores eran en términos de empleo claves pero, para la última brecha de tiempo se observa una disminución significativa en la importancia relativa que presentaban (ello en términos proporcionales), esto sería indicativo del proceso de transformación que va experimentando la economía, al pasar de ser una primaria a secundaria y de servicios.

Actividades que han mantenido su importancia en Magallanes son minas (aún cuando se observa una baja importante en 2004) y electricidad, gas y agua (E-G-A).

En referencia a lo ocurrido en Chile, los principales cambios se presentan en los años 1988, 1992 y 1993, con incrementos respecto a la etapa anterior de un 7\% para 1988 y de un 5\% para los restantes. En el caso de 1988, las ramas que más incrementaron el número de empleados fueron construcción, industria manufacturera y, trasporte y comunicaciones con un 31, 11 y 9\% respectivamente. Por su parte en 1992, los sectores que más cambiaron en pro de aumentar su capacidad son los de electricidad, gas y agua (17\%), comercio (9\%) e, industria manufacturera y transporte y comunicaciones, ambas con un 8\%. Finalmente, en 1993 los incrementos se justificarían por las ramas construcción (20\%), servicios financieros (19\%) y electricidad, gas y agua con un $17 \%$.

En base a lo comentado, y en referencia a lo tardío en que reacciona el mercado laboral local respecto al nacional (aproximadamente 3 años), se puede apreciar que efectivamente no existe un correlato inmediato en la generación de empleo. Lo que ocurre a nivel nacional, no es coincidente para igual fecha o periodo inmediato con lo que acontece

5 La nomenclatura empleada es la siguiente: A-S- C y $\mathrm{P}=$ Agricultura, silvicultura, caza y pesca; Minas= mineria y canteras; Industria= Industria Manufacturera; E- G- A= Electricidad, gas y agua; construcción= Construcción; Comercio $=$ Comercio, restaurantes y hotees; $\mathrm{T}$ y $\mathrm{C}=$ Transporte y Comunicaciones; S. Financieros= Servicios Financieros; Ss. Cc y Ss= Servicios Comunales y Sociales (incluye personales). 


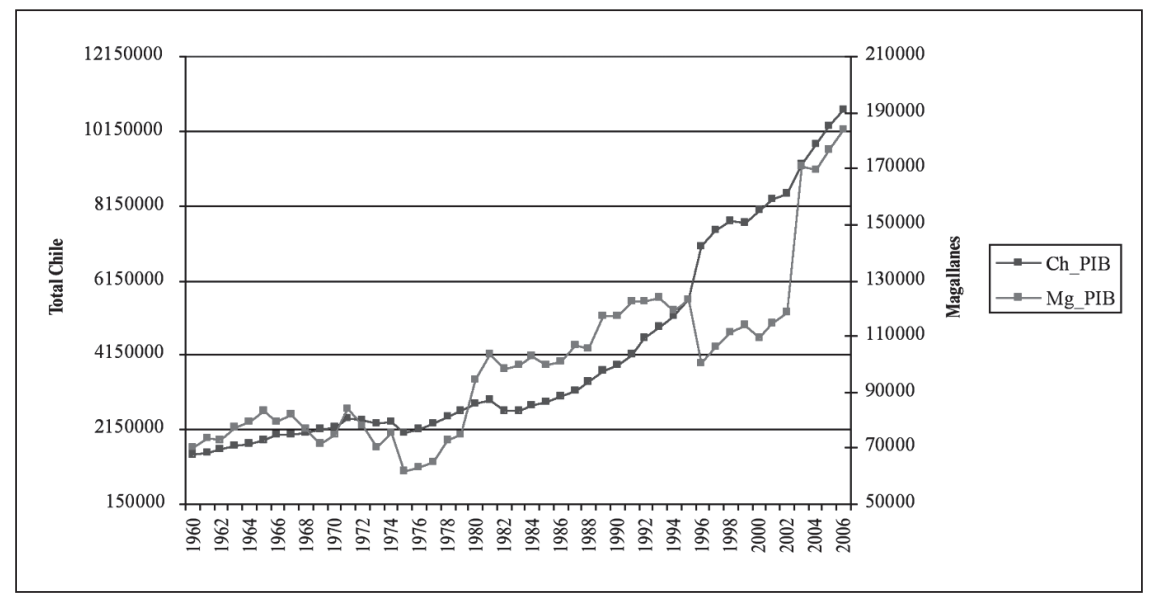

Fig. 3. Producto Interno Bruto Regional para Chile y Magallanes (1960- 2006, millones de pesos de 1986). Fuente: CIEPLAN y Banco Central.

en Magallanes, dado este desfase que en promedio es de 3 años, entre el país y la región. En esta línea, se observa que los sectores que responden en forma más rápida frente a los vaivenes de la economía nacional son, agricultura, silvicultura, caza y pesca, junto con electricidad, gas y agua, comercio y, transporte y comunicaciones, que lo hacen aproximadamente con un desfase de 2 años, mientras que minas, industria manufacturera y construcción, llegan al extremo de reaccionar entre 4 a 6 años después.

En una segunda etapa, se analiza lo relativo a la variable PIB regionalizado para el periodo 1960 a 2004 (Fig. 3). De este grafico lo primero que resalta, es la baja que experimentó el producto magallánico durante los períodos 1975-1979 y 1996-2002.

Respecto a la identificación de ciclos se visualizan 3, el primero para los años 1960- 1975, un segundo entre 1975 y 1995 y, un último que se inicia en 1995 y termina con la serie en 2006.

En lo referente al año de mayor variación, se observa que para el caso de Magallanes es en 2003, mientras que para Chile en 1996.

La mayor baja del producto que se observa en Magallanes -durante los años 1995 y 1996-, sería debido a la disminución que experimentaron los sectores, agropecuario, silvícola, caza y pesca (63\%), minería (49\%), industria manufacturera (51\%) y comercio (48\%). En lo referente al auge que se observa para los años 2002-2003, habría sido causado por los incrementos en las ramas industria manufacturera (152\%) y construcción (108\%).
En el caso de Chile, la mayor baja para los últimos años ocurre en el período 1998- 1999 con cerca de $0.5 \%$, justificado por la disminución de las ramas construcción (aproximadamente 10\%), electricidad, gas y agua (4.75\%) y comercio (4.5\%). Respecto a las mayores alzas, éstas se dan en varios años: 1989 (9\%), 1992 (11\%), 1995 (9\%), 1996 (25\%) y 2003 (9\%). Centrándose sólo en ésta última, se observa que la causa habría sido el incremento de las ramas pesca (14\%), transporte y comunicaciones (5\%) y, productos del agropecuarios (4.5\%).

En referencia a la identidad regional, desde la perspectiva histórica del $\mathrm{PIBr}$ se puede comprobar en base a la Fig. 4, la importancia que presentó en los primeros años para la región la minería, prácticamente todo el producto de los años 60 se justificaba por esta rama, situación que sin dudas ha cambiado a lo largo del tiempo, aún cuando ello, no ha significado una pérdida en importancia del sector para la época de hoy, esto es, del año 2000 en adelante, la rama como tal sigue siendo importante, la tercera en participación para ser precisos.

De acuerdo a la evolución del producto, también se ven otras situaciones que van a la inversa de la recientemente comentada, por ejemplo, los sectores industrias manufactureras y otros (administración pública y resto), si bien han mostrado episodios de quiebres importantes a lo largo de la serie, también dan claras señales de lo importante que ellas se han tornado en la región, en especial el caso de la industria manufacturera, la que en la actualidad es tan importante como lo fuera en antaño la minería. 


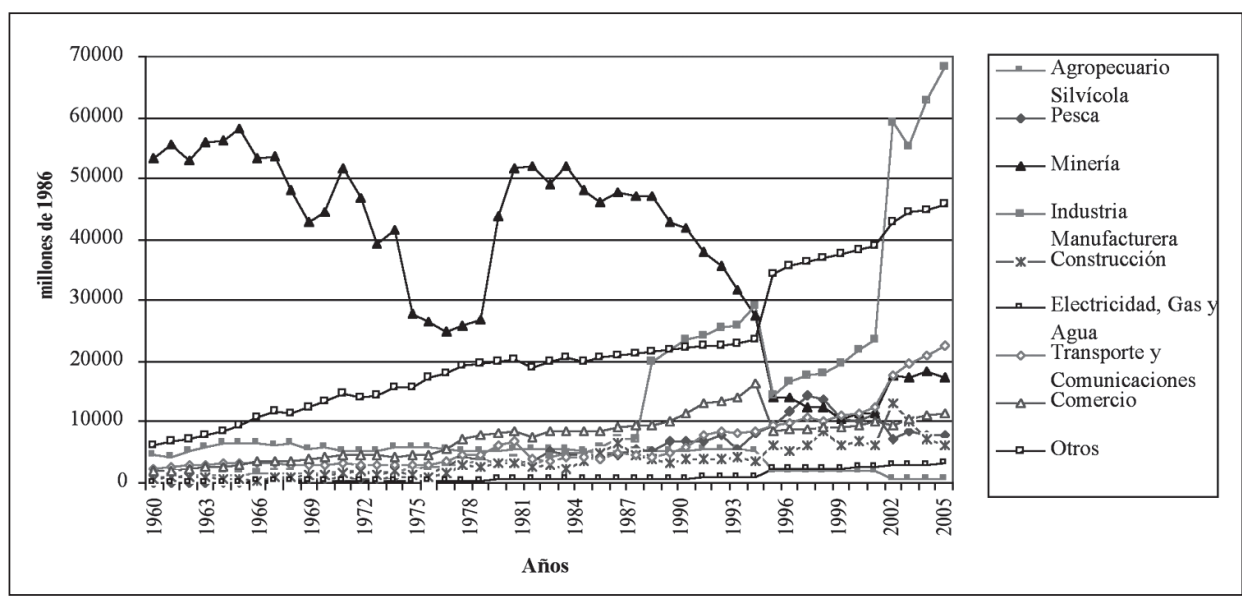

Fig. 4. Producto Interno Bruto Regional para Magallanes (millones de pesos chilenos de 1986). Fuente: CIEPLAN y Banco Central.

Una situación como la comentada anteriormente, pero no tan marcada como ellas se da con las ramas agricultura y silvicultura y pesca, si bien estas a comienzo de los 60 eran importantes, en el caso de las primeras, su participación en el total cada vez se van haciendo menos significativas, sin embargo, en el caso de la pesca, esta aún cuando ha presentado episodios de repunte importante, como el ocurrido en el año 1995, su peso relativo no se ha incrementado tan notoriamente como el de la industria manufacturera, esto es, su importancia en estos últimos años, si bien ha aumentado, ello no ha sido muy significativo.

Respecto al punto anterior, es interesante el caso de la rama otros (administración pública y otros servicios), pues es una manifestación de la evolución que muestra la economía, en este sentido, y en base a la dinámica del conjunto local, se observa cómo la región en unos inicios presentaba una estructura muy básica, esto es, Magallanes se caracterizaba por contar con ramas que, por un lado, no demandaban insumos y si lo hacían era en muy baja cuantía y, por otro, también estaban las que vendían semi o completamente elaborado algo. Como se ve este tipo de sectores eran los que componían la economía en la década de los 60, sin embargo, estas fueron perdiendo importancia a finales de los años 70 aproximadamente, donde la región en base al $\mathrm{PIBr}$ manifiesta un cambio. Esto es, de poseer sectores más orientados hacia la oferta, pasa a una economía en donde se demanda y oferta simultáneamente, tal como ocurre en las economía desarrolladas, esto es, de basar su economía en productos básicos como los comentados, se transforma en una economía manufacturera y de servicios, condición propia de las economía que están en proceso de desarrollo. Es decir, ahora son ramas cómo las administraciones, servicios, transporte y comunicaciones, actividades de ocio, etc, las que caracterizan a la región y, no las que en antaño estaban más ligadas a la industria primaria (agricultura, minera, etc).

\section{Otros Antecedentes}

Como algo complementario a lo anterior, se analizan a continuación la Fig. 5, referida al Índice de Actividad Económica Regional (INACER 19962008), en esta línea, se observa cómo la actividad ha ido variando; en general, ha manifestado un alza constante para el período señalado, por otra parte, si dicho gráfico se complementa con la Fig. 4, se observa con más detalle que la economía magallánica en la práctica ha experimentado un incremento significativo de su producción en los últimos años, ya que cuando se analiza el INACER excluyendo el Metanol -commodity característico de la región-, se observa que este ha mantenido una tendencia en ascenso desde el año 2003, situación que ocurriría a la inversa cuando éste se incluye. Sin embargo, estos incrementos no se han reflejado en los principales agregados económicos, pues estos se han visto afectados por las bajas que manifiesta dicho derivado (de cierto modo frenados), en este sentido, se observan dos aspectos que merecen la 


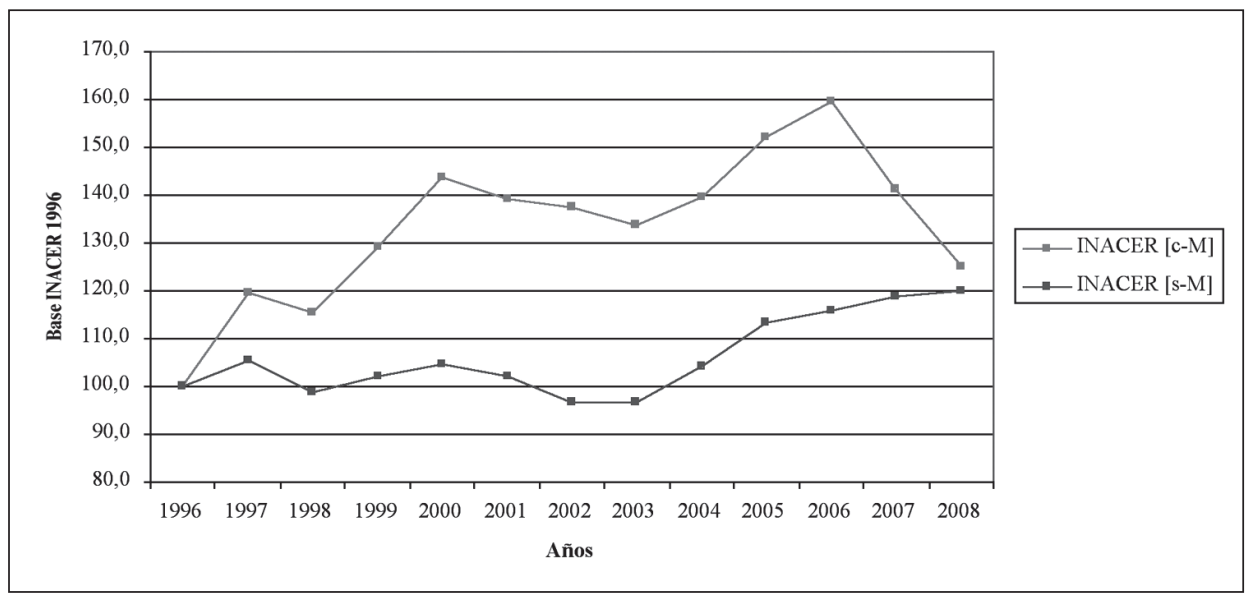

Fig. 5. Índice de Actividad Económica Regional Promedio para Magallanes (INACER 1996- 2008, base 1996).

Fuente: INE- Magallanes.

pena comentar. Primero, la aparente incidencia que tiene la industria química en la actividad local, esta primera visión -sesgada de momento-, manifestaría aparentemente lo vulnerable que es Magallanes frente a las variaciones que muestran los mercados internacionales - dependencia propia de cada región que cuenta con algún commodity, pues sus precios se fijan en mercados externos. En este sentido, esta actividad que pareciera ser una necesidad de desarrollo local, por lo visto no lo es, pues la industria química no tiene una ingerencia significativa en el desarrollo regional, esto último basados en las tendencias que muestran el producto e INACER. Segundo, al restar de la economía el metanol, como ya se comentara, se observa que ella tiende al aumento, esto es, en la práctica pareciera ser que, la industria local ha ido perdiendo dependencia frente a esta actividad, esto es, la industria en general, se ha ido abriendo espacios en otros quehaceres, como por ejemplo, en el mercado de los licores, cervezas y molinería.

\section{Aplicación Shift- Share}

Antes de proceder con la aplicación shiftshare, se debe recordar que se parte de la premisa que la elección de los episodios en donde se detectan cambios estructurales será para el periodo 1986 y 2008 y en base a la variable empleo, a partir de lo anterior, se determinará en qué momentos se presentan los cambios estructurales que se van a considerar. Una vez establecido esto, se debe decidir para qué cambios se realizará el estudio, esto es, los acaecidos en Chile, en Magallanes o para una mezcla de ellos.

Posteriormente y, una vez definido lo anterior, se sugiere corroborar tales resultados con las variaciones que ha manifestado el PIBr. Sí existe evidencia de la coincidencia en tales cambios estructurales, es decir, si se confirma que las variaciones que manifiesta la variable empleo ocurren en similares fechas con los detectados con el PIBr, se procede a una doble aplicación, en caso contrario, se debe establecer bajo qué condiciones se definirá cuáles serán los años a tratar y si procede variables a emplear.

Con respecto al primer aspecto que, pasa por responder qué años considerar para la aplicación de la metodología shift- share (clásica). Se debe optar por elegir al menos entre uno de los tres escenarios que a continuación se indican. Primero, se puede partir por evaluar los años en que la economía local gozaba de altos empleos -o productividad-, sin embargo se hace notar que, tomar esta postura significa de alguna manera apartarse de la realidad nacional y considerar esta economía en forma independiente, esto es, que su desarrollo no se ve afectado por lo que ocurre a nivel nacional, pues se recogería en los resultados los cambios de dinámica basado en los hechos locales y no nacionales. Segundo, se puede analizar la situación regional bajo el contexto de las características que presentaba su economía cuando era la nacional la que se encontraba en época de altos empleos o producción o, bien en un cambio estructural favorable, esto es, ver en que situación se encontraba la economía local, cuando es la nacional 
la que rige la pauta de desarrollo. Finalmente, se puede presentar un análisis en donde se parta de la base que es en la economía local en donde existe un episodio de altos empleos y se tome como tiempo de referencia, esto es, el instante final de la dinámica, aquel en donde sea la economía nacional la que está en un ciclo de cambios favorables -máximo auge-, de esta forma se incluye en el análisis el efecto del empuje de la economía local -el cual es tomado como año base-, y se observan sus cambios cuando es la economía nacional la que presenta altos incrementos -fin del ciclo-, el hacer esto implica revisar los cambios que surgen tomando como punto de partida una economía local dada una época de bonanzas $y$, como término, otra con un alto dinamismo, esto permitiría observar qué cosas han cambiado a nivel local y cuáles deben mejorar con el fin de mantener la propia dinámica y a su vez sumarse al dinamismo nacional.

En referencia al párrafo precedente, y dada la importancia que tienen las repercusiones de las políticas económicas nacionales, no es bueno el omitir este aspecto. En este sentido, el hacerlo significa tratar al conjunto de regiones como casos aislados del contexto nacional, lo que en la práctica no ocurre. Dado esto, una alternativa pasa por considerar ello y centrar las respuestas en la economía local, por otro lado, y en consideración a que este estudio también busca establecer cuáles son las actividades que dan significado a la economía materia de estudio, esto es, con las que se puede identificar el desarrollo de ella, también es valido considerar el segundo escenario.

Sobre la base de lo anterior, se realizara la aplicación shift-share (clásico) en base a la PEA por rama de actividad y los cambios estructurares que presenta esta variable para el contexto local, acto seguido, se replicará el ejercicio, pero basados en los cambios estructurales detectados en la economía nacional. De esta forma se tratará en conjunto dos visiones económicas, una primera instancia en donde se observará en que condición se encontraba Magallanes frente a Chile cuando el primero estaba en una época de esplendor, y en una segunda, se sabrá que actividades primaban tanto en la economía local como nacional, cuando es el país el que presenta condiciones favorables, adicionalmente, se comprobaran dichos resultados en base a la variable PIBr.
En base a lo observado y comentado, si sólo se considerase la variable empleo a nivel nacional los años a revisar debieran estar entorno a 1998 y 2005 , esto producto que en ellos se observan quiebres que, por un lado, indican una nueva estructura en la composición del empleo y, por otra, episodios de auge. Paralelamente, en los años 1998 y 2006 la variable $\mathrm{PIBr}$, da señales de un comportamiento similar, por tanto, se acerca a los cambios que experimento el empleo.

De igual forma para la condición base, esto es, la época en que Magallanes experimenta el cambio en base a la PEA, se considerarán adecuados los años 1999 y 2003, años en que el PIBr, también presenta alteraciones respecto a los años anteriores.

Además del punto anterior, se debe tener presente que, cuando se trabaja bajo la premisa de una dinámica económica, se está trabajando con un cierto periodo que en ocasiones es difícil establecer, ya que depende de la distintas fluctuaciones de cada zona, región o país. Sin embargo, y como ya se comentara, se recomienda tomar lapsos de 10 ó 5 años basados en los hechos nacionales, a objeto de evitar la existencia de datos distorsionadores de la realidad, esto es, episodios de continuidad y no de cambio real.

Por tanto y considerando la proximidad de las cuatro fechas detectadas (1998; 1999; 2003 y 2005), se cree que el año adecuado a considerar como de partida para los fines aquí perseguidos es el de 1999, dado que es una época en que Magallanes gozaba de cierto esplendor y coincide con una tendencia al alza del PIBr, finalmente, el ciclo terminaría en 2005. Hacer esto significa revisar cómo una estructura local exitosa cambia frente al dinamismo que trae la economía de referencia, en este caso Chile y además, se cumple con una revisión que supera los 5 años.

\section{EL CASO DE MAGALLANES EN EL CONTEXTO NACIONAL}

Al observar el comportamiento y desarrollo económico de Magallanes, se nota que ofrece una serie de ventajas tanto comparativas como competitivas, llamando la atención que su crecimiento fuese de un 12\% durante el período 2005- 1999, pues la media nacional alcanzo un 9\%, es decir, Magallanes creció para el citado ciclo más que el 
promedio de la actividad económica chilena, lo que sería fundamentado por el vertiginoso desarrollo que han tenido en esta región los sectores comercio, restaurantes y hoteles (28\%), junto con construcción (27\%) y transporte y comunicaciones (36\%).

Respecto a la participación del empleo en cada rama de la producción regional durante 1999, el 30\% de ellos estuvo radicado en los servicios comunales y sociales, por su parte, la industria manufacturera y el comercio, representaban el 28\% (14\% cada una) y, un $11 \%$ aproximadamente de las personas laboraban en el sector agrícola, silvicultura, caza y pesca. Para el año 2005 se observan pocos cambios, el 30\% de la población trabajaba en el sector servicios comunales y sociales (igual que en 1999), un $18 \%$ en comercio (un $4 \%$ más que en 1999), un $12 \%$ en trasporte y comunicaciones (3\% más que en 1999) y un $10 \%$ en la industria manufacturera (ver tablas 2 y 9 del anexo).

En lo que respecta a la distribución interregional de las ramas de producción en el total nacional para 1999, menos del 1\% del sector agricultura, silvicultura, caza y pesca, se contrata en la región, el 5\% en minas, el $1 \%$ en industria manufacturera, un $2 \%$ en electricidad, gas y agua, un 1.5\% en construcción, menos de un $1 \%$ en comercio, un $1.5 \%$ en trasporte y comunicaciones, y un $2 \%$ aproximadamente entre servicios financieros y comunales y sociales, es decir, estos datos indicarían la escasa participación que tiene en términos de empleo la región de Magallanes en el contexto nacional.

$\mathrm{Al}$ analizar la especialización relativa o interregional (cociente de localización para el año 2005; tabla 3 del anexo), es claro que la región se especializa en la contratación de personas ligadas al sector minas y canteras y, de trasporte y comunicaciones, e igualmente importantes, pero no tan relevantes como las anteriores, serían los sectores electricidad, gas y agua junto con construcción, lo cual coincide con la concentración absoluta de dichas actividades en la región.

Al revisar el coeficiente de especialización o grado de diversificación (vector) para 2005 y 1999 (tablas 4 y 5 del anexo), se notará que cuando se compara a Magallanes en su conjunto con el resto de regiones, éste se ve más próximo al promedio nacional en 2005 que en 1999, aunque hay que hacer notar que, en ambos casos la región está muy por debajo de dicha media, lo anterior indicaría que la actividad local para ambos años es muy poco diversificada -de hecho, es la tercera región menos diversificada-, lo que induce a proponer que en la región se tome un gran compromiso con el resto de las actividades, esto es, se deben potenciar aquellas ramas que no sólo den más dinamismo a la actividad local, sino que también favorezcan la diversificación de actividades, de esta forma, se favorece aunque no garantiza a futuro un mayor crecimiento.

Con respecto a la base económica, la cual explica cuánto queda en la región y cuánto se exporta, es decir, indica la cuantificación de las demandas internas y externas, mostrando los cambios que han ocurrido en estas para la serie de tiempo anteriormente aludida. En 1999 la actividad exportadora se centraba en los sectores minas, electricidad, agua y gas, construcción, transporte y comunicaciones y servicios comunales y sociales, de ellas las menos significativas resultaron ser electricidad, gas y agua junto con los servicios comunales y sociales, tales demandas tuvieron notorios cambios en 2005 (tabla 6 del anexo), durante ese año aumento considerablemente la demanda de personas dedicadas al trasporte y comunicaciones, ella prácticamente se doblo, mientras que en minas y canteras se observa una leve disminución. En el resto de las ramas no se aprecian mayores cambios, esto es, las demandas se mantienen de forma similar para ambos años.

Desde otra perspectiva, se observa que la región esta sufriendo un rápido crecimiento en comparación al resto del país en sectores tales como el de servicios financieros. Sin embargo, también se observa que otras actividades como transporte y comunicaciones junto con comercio, si bien han crecido en la región, la tasa con que lo hacen es menor que la registrada a escala nacional.

Al revisar la dinámica de la estructura económica regional, se aprecia la evolución o involución de la especialización regional en las distintas ramas de actividad, o de la región en su conjunto (coeficiente de reestructuración, en anexo tablas 10 y 11). Del análisis de los datos procesados, es fácil vislumbrar que la única región que experimentó un cambio relativamente importante fue la de Aysén (vector igual a 0.1094), y en segundo lugar, aparecería la de Magallanes (vector igual a 0.0888). En el resto de regiones prácticamente no se aprecia la existencia de cambio alguno en su conjunto. 
Para el caso particular de Magallanes, se destaca el aumento de los sectores servicios, esto es, comercio, transporte y comunicaciones, financieros y comunales y sociales, estos incrementos, dan una señal positiva de la dirección que está tomando la estructura magallánica, pues ella se acercaría a la de una economía más desarrollada, por lo tanto, estas modificaciones debieran implicar a futuro un mejor posicionamiento de la economía a nivel nacional, lo que ya se comienza a vislumbrar de acuerdo a los datos de empleo y actividad económica registrados para los últimos años.

Las fuentes que produjeron las distintas dinámicas o cambios de la estructura económica regional se recogen del diferencial estructural 2005-1999 (en anexo tablas 12 y 13), el que nos indica que las regiones del norte (Atacama y Antofagasta) tienen una situación privilegiada, ya que ellas presentan un efecto total positivo, debido a que el efecto diferencial y el estructural son justamente así, es decir estas regiones en 1999 tenían una estructura económica similar a la estructura económica de la nación, y siguieron basando su economía en las actividades que justamente presentaron un mayor crecimiento en aquella época, alcanzando una competitividad superior a la del promedio nacional, situación que se continuó hasta el año 2005. Tal situación no se observa en Magallanes, pues el efecto total es negativo, esto ocurre producto de que el efecto diferencial es muy alto y negativo, y en el caso del estructural es muy bajo aunque positivo (tabla $13 \mathrm{del}$ anexo, -5162 y 28 respectivamente), como se ve, tales valores nos señalan que, Magallanes, pierde hipotéticamente alrededor de 5134 puestos de trabajo para el periodo considerado, pues, su estructura dista mucho de la estructura nacional, esto es, la dinámica económica de Magallanes no van en sintonía con la del país, es decir, las necesidades de empleo que se van produciendo en el país, no son captadas por el dinamismo económico regional.

En lo que respecta a la concentración relativa de la actividad económica (coeficiente de localización, tabla 7 del anexo), se aprecia que las ramas minas, electricidad, gas y agua, construcción, comercio y transporte y comunicaciones, están relativamente concentradas en la región de Magallanes, situación algo inquietante, pues los mayores ingresos a nivel nacional se producen a través de los sectores agricultura, silvicultura, caza y pesca junto con los servicios financieros, es decir, con el tiempo Magallanes debería tender a modificar su estructura, a fin de que la región re-oriente sus especialidades, hacia otras más lucrativas.

\section{Empleo y $\mathrm{PIBr}$ dos variables en disputa}

Una forma de evaluar los resultados anteriores es contrastando, por ejemplo, estos con los obtenidos para el producto interno bruto (PIB regionalizado); para ello habría que centrase en los principales coeficientes y multiplicadores emanados de la técnica utilizada, y en base a tal comparación, emitir un juicio que responda a la identidad magallánica del último tiempo, esto es, lo que ha caracterizado a Magallanes en el período 2005- 1999 y a partir de esta, sugerir algunas reflexiones.

Con respecto al multiplicador keynesiano para la PEA y PIBr (tabla 2), se observa para la

Tabla 2. Multiplicador Keynesiano y Base Económica según empleo y PIB por años para Magallanes.

\begin{tabular}{|c|c|c|c|}
\hline \multicolumn{2}{|c|}{ Empleo } & \multicolumn{2}{|c|}{ PIB } \\
\hline 2005 & 1999 & 2005 & 1999 \\
\hline \multicolumn{4}{|c|}{ Multiplicador Keynesiano } \\
\hline 9.94 & 10.09 & 3.13 & 4.05 \\
\hline \multicolumn{4}{|c|}{ Base Económica } \\
\hline- & - & Pesca & Pesca \\
\hline Minería & Minería & Minería & Minería \\
\hline Electricidad, Gas y Agua & Electricidad, Gas y Agua & - & - \\
\hline- & - & Industria & - \\
\hline Construcción & Construcción & - & - \\
\hline Transporte y Comunicaciones & Transporte y Comunicaciones & Transporte y Comunicaciones & Transporte y Comunicaciones \\
\hline Ss. Sociales y Comunales & Ss. Sociales y Comunales & - & - \\
\hline
\end{tabular}

Fuente: Propia. 
primera una disminución de aproximadamente un $2 \%$ y, una baja del 23\% para la segunda, lo anterior se interpreta como una disminución del impacto que tiene la base económica en la generación de empleos y producción ${ }^{4}$, por ejemplo, el multiplicador de empleo para el año 2005, era de un 9.94 para Magallanes; esto se interpreta de la siguiente manera, por cada puesto de trabajo que se hubiese generado en la base económica que, para este caso la formarían las ramas minería, electricidad, gas y agua, construcción, trasporte y comunicaciones y servicios sociales y comunales (tabla 2 ), se hubiesen creado hipotéticamente nueve puestos de trabajo adicionales, o visto desde otra perspectiva, si el empleo de los sectores que forman la base económica hubiesen aumentando en un 10\%, el empleo total de la región lo habría realizado hipotéticamente en un 99.4\%. Para el caso del PIB, este se interpreta como las veces en que la producción se habría incrementado por cada unidad adicional producida en la base, esto es, 3.13 veces.

En lo referente a la base económica (tabla 2), se aprecia que ella no es la misma, esto es, cambia según la variable y año que se considere, sin embargo, se observa una similitud común para los sectores minería y trasporte y comunicaciones, esto es, la región se identifica más para el periodo estudiado con tales ramas, las que se entiende formarían el vertebrado del entrado económico regional para data analizada. Esto último, se presenta como una evidencia de los posibles impactos que se puedan producir en la economía magallánica, pues, desde dos variables distintas se comprueba cuál es el impacto hipotético en, por un lado, la generación de empleo y, por otro, en la producción de las distintas actividades económicas.

Distribución interregional absoluta de las actividades económicas en 2005 y 1999

Lo que continua, explica en términos de aportes, cuál es la participación en forma individual de las distintas regiones en los diferentes sectores (tabla 2 del anexo). Al observar lo concentrado que está una actividad realizada en Magallanes pero en

6 La magnitud del multiplicador debe ser entendida había consideración de la agregación utilizada, pues a mayor agregación, mayor multiplicador, luego con un nivel menor de agrupación, el multiplicador debiera reducirse. relación al ámbito nacional, se aprecia que para el caso local durante el 2005, ello no ocurre, cuando más se llega al extremo del 1\% (gas, electricidad, agua, construcción, comercio, transporte y comunicaciones y servicios comunales y sociales), esto es, la participación en términos de aporte a la población económicamente activa por sector que entrega Magallanes a la nación, es baja, y en el caso del PIB, sólo el sector pesca tiene una ingerencia ligeramente significativa (5\%), luego participan en igual medida la industria minera y manufacturera con un $2.5 \%$ cada una.

En referencia a 1999, se da una condición más marcada, en especial para el caso del PIB y el sector pesca, no así para el empleo que presenta la misma composición que en 2005. Los aportes que la región realizaba al PIB del sector pesca eran más importantes, esto es, la región entregaba un $13 \%$ al $\mathrm{PIBr}$ del sector pesca en el total nacional, es decir, en términos de ingerencia, la actividad pesquera Magallánica era importante en el contexto nacional.

\section{Especialización absoluta por sectores para 2005 y 1999}

La especialización absoluta, se observa a partir de la propia estructura económica regional, esto es, en base a la participación que presentan las distintas ramas en el total de la economía regional. Tal patrón por tanto, señalará qué actividades caracterizan a Magallanes.

Para el año 2005 y, una vez que es omitida la variable empleo en la administración pública (tabla en 1 anexo), se observa que a nivel país no existe una especialización absoluta, de igual forma, dadas estas condiciones se aprecia una cierta importancia en términos de participación en las ramas agricultura, selvicultura, caza y pesca junto con comercio, ya que entre ellas albergan aproximadamente al 40\% de la población. Con respecto a la variable PIB, se observa que a nivel de país para tal año tampoco se da una alta concentración. Sin embargo, hay un aspecto distinto de comentar con esta variable, de acuerdo a la producción del año 2005, se puede constatar que existe una mayor diversificación en términos de participación, que además es distinta a la manifestada por la variable empleo, esto es, en el caso del PIB, a nivel nacional en 2005 , se observa que son 
importantes las ramas de la minería, transporte y comunicaciones, comercio, restaurantes y hoteles, industria manufacturera y servicios financieros, las que no coinciden con las detectadas con la otra variable de referencia.

La situación de Magallanes en 2005 y 1999 en base a la variable empleo (tablas 1 y 9 del anexo), manifestaba que en ambos años existe una alta participación del sector administración pública (30\%), y en el resto de las ramas, existe una aportación, en general, más bien homogénea, presentándose las mayores contribuciones para el 2005 en los sectores, industria (10\%), comercio (18\%), transporte y comunicaciones (12\%) y, en 1999 para las ramas agricultura (11\%), industria (14\%), construcción (10\%) y comercio (14\%), estos valores aún cuando señalarían que la actividad regional es más bien diversificada en ambos casos, también indican, por un lado que, para el 2005 ó 1999, no existe una actividad característica única de la región $y$, por otro que, en 1999, Magallanes era más diversificado que en 2005.

De la variable PIB se desprende que, la mayor concentración en el 2005 se dio en la industria manufacturera (35\%), además también sería importante aunque en menor medida la producción que emana de los sectores minería (10\%), transporte y comunicaciones y administración pública (12\% respectivamente cada una). En 1999, la situación era similar, aún cuando se aprecia que sectores tales como la pesca tenían una mayor participación (12\%), minería (11\%), industria (15\%) y administración pública (12\%).

En base a lo comentado, se aprecia la existencia de un divorcio entre los aportes que realizan los distintos sectores y las variables utilizadas, en este aspecto, y considerando además la lectura que se obtiene del INACER regional, se puede sostener que, tales divergencias serían explicadas por el metanol, luego y en consonancia con los antecedentes recogidos, soy de la opinión que, Magallanes más bien se identificó en los años 2005 y 1999 con ramas vinculadas a los servicios, es decir, habría dejado de ser una región que dependía históricamente de ciertos recursos naturales, para ahora trasformarse en una que más bien presta servicios, lo cual estaría en línea con el desarrollo que muestra el país.

\section{Especialización regional para 2005 y 1999}

La especialización regional, es obtenida a partir del coeficiente de especialización, el que básicamente compara que regiones son más o menos especializadas, en función de las similitudes y diferencias que se manifiesten entre las estructuras económicas regionales y la que se toma como marco de referencia, en este caso el país.

De las tablas 4 y 5 del anexo, se observa que la mayor especialización en términos de empleo se da en la región de Antofagasta (0.225), por su parte Magallanes en 2005 y 1999 presentó unos valores que la situaron cómo la tercera región en ambos casos menos especializada (0.101 y 0.099 respectivamente); tales valores indican que la región para esos años presentaría una estructura similar a la de del país, si en ello se considera la variable PEA.

Por otra parte, cuando se emplea el PIB, tal indicador señala que Magallanes es la quinta región más especializada en 2005 (mayor valor 0.536 (Antofagasta); menor valor; 0155 (Valparaíso); región; 0.319) y, la tercera menos especializada en 1999 (mayor valor 0.577 (Antofagasta), menor valor 0.153 (Valparaíso), región; 0.222).

Lo anterior, señala que, si se considera la variable empleo, la región presenta una estructura similar a la del país, lo cual es una buena señal en términos de política económica, ya que su dinámica obedecerá a la inercia que trae consigo la economía nacional, no quedando sujeta por tanto a los avatares regionales. Sin embargo, la variable $\mathrm{PIBr}$ indica lo contrario, esto es, que la región obedece a un comportamiento distinto del nacional, lo cual iría en desmedro del crecimiento local que se pueda deber a políticas nacionales, por tanto, es un aspecto a corregir, esto es, tanto la producción regional como su vertebrado y entramado, deben acercarse a la estructura nacional.

\section{Dinámica de la distribución interregional para 2005 y 1999}

La idea que persigue este apartado es, observar el proceso de relocalización de las distintas ramas a nivel regional, es decir, se analizan los distintos grados de concentración geográfica que presentan tales sectores. Aún cuando soy conciente que tal transformación o cambio es lento y se requeriría 
considerar mayor tiempo para entregar respuestas más definitivas, se es de la idea que tal análisis ayuda a comprender el proceso al menos parcialmente, en este sentido, se justifica su inclusión pues indica la dirección que han tomado las ramas que han iniciado el proceso.

Para el período 2005- 1999 (tabla 14 y 15 del anexo), la población económicamente activa señalaba que las ramas que mostraron una mayor redistribución territorial de sus actividades son, electricidad, agua y gas (0.17), minas y canteras $(0.10)$ y construcción (0.074), en el caso de la primera, la población habría aumentado en la región del G. L. B. O'Higgins, dicha cambio habría sido compensado por el resto de las regiones en forma homogénea, no observándose una baja importante en ninguna de ellas. En el caso del sector minería, los cambios son localizados, y estos habrían sido en las regiones del norte del país (Tarapacá, Antofagasta y Coquimbo), el origen de la población sería muy distribuido, esto es, ninguna región experimentó un cambio significativo en sus participaciones sectoriales. Finalmente, el sector construcción, en O'Higgins presentó un aumento importante de mano de obra, siendo compensado por el resto del país, pero principalmente por las regiones vecinas (Metropolitana y de Valparaíso).

$\mathrm{El} \mathrm{PIBr}$ por su parte indica que, los mayores cambios se observan en las ramas pesca, industria y electricidad, gas y agua. En el caso de pesca, el cambio afectaría a la región de Magallanes, pues su baja en la producción habría compensado el aumento que experimentó la región de Los Lagos (la mayor de todas), esto es, la pérdidas de producción de Magallanes habría compensado en su totalidad la ganancia de actividad sectorial que se aprecia en la región de Los Lagos. En el caso de la industria manufacturera, los cambios se deberían al incremento de la producción que se manifestó en las regiones de Valparaíso, Bío.- Bío y Magallanes, incremento que habría sido compensado por la disminución de la actividad manufacturera que se da en la región metropolitana. Finalmente, el sector construcción se ve fuertemente incrementado en la región metropolitana, tal alza sin embargo, habría sido compensada por la baja practicante total que se da en el conjunto de regiones del país, siendo la excepción la región de Antofagasta, el resto todas compensaron el alza con homogéneas pérdidas en la producción.
Dinámica de las estructuras

regionales para 2005 y 1999

La idea de revisar los cambios estructurales, obedecen al interés que existe por ahondar en la forma en que las distintas regiones han variado su vertebrado. Para ello se recurre al coeficiente de reestructuración (tablas 10 y 11 del anexo), el cual sobre la base de dos fechas concretas, en este caso 1999 y 2005, compara los cambios que manifiestan las regiones en sus respectivas especializaciones, un alto valor indicará un cambio más significativo en la estructura, siempre y cuando este tienda a la unidad.

De la variable empleo se desprende que en Chile existen dos regiones que presentaron cambios estructurales, aunque se hace notar que ellos no son significativos, las regiones en concreto son la de Aysén (0.10) y la de Magallanes (0.088).

En el caso que nos ocupa, tal cambio sería originado básicamente por las ramas comercio y transporte y comunicaciones $y$, en menor grado por los sectores servicios financieros y comunales y sociales, tales variaciones fueron favorecidas por las bajas que se dan en el resto de las ramas y, en forma especial por la que presentó la industria manufacturera.

$\mathrm{El} \mathrm{PIBr}$, por otra parte, indica que el mayor cambio estructural a nivel nacional se dio en la región de Magallanes (0.225) y se habría originado por la alteración que se manifestó sólo el sector transporte y comunicaciones, el resto de las ramas habría facilitado tal cambio, esto es, la caída que expresan el resto de las ramas, habría compensado la mayor participación de las actividades vinculadas al transporte y comunicaciones.

\section{Descomposición de la dinámica de actividad económica regional para 2005 y 1999}

Lo que continua es una exploración en base a las variables población económicamente activa (PEA) y PIB, de la dinámica que experimentan las regiones, en este caso Magallanes. La idea es señalar cuánto del crecimiento económico regional es causado por las dinámicas que traen los distintos sectores en el país, esto es, se hará una indagación sobre lo competitivo que puede ser una región (efecto diferencial, tabla 12 del anexo), además se cuantificará cómo la 
especialización regional se vincula con el mayor o menor dinamismo que presenta el país, esto es, se observa si la región en el momento inicial, presentaba una estructura orientada hacia las actividades que a nivel nacional mostraban un mayor crecimiento (efecto estructural, tabla 13 del anexo).

Un efecto total positivo (diferencial y estructural), será indicativo de que la región mostró un crecimiento relativo mayor que el del patrón de referencia en su conjunto, esto es, se estará frente a una región que no sólo presenta un vertebrado económico inicial caracterizado en la especialización de aquellas ramas que muestran un mayor crecimiento a nivel de país (estructural), sino que además, sus ramas presentarán una competitividad tal (efecto diferencial), que no sólo es alta a nivel regional sino que también en el nacional.

En el caso de Magallanes, según la PEA y el análisis diferencial- estructural, se constata que el efecto total es negativo (-5130), producto de que el efecto diferencial es mayor en términos absolutos (negativo; -5162) que el estructural (positivo; 28), esto es, Magallanes en 1999, aún cuando presentaba una mínima especialización en actividades de mayor dinamismo a nivel de país (comercio, trasporte y comunicaciones y servicios financieros), sus ramas presenta una competitividad a nivel local que ha sido baja, lo que ha significado un menor crecimiento local respecto al alcanzado por las mismas a nivel nacional.

En base a lo anterior, se aprecia que la región ha ido perdiendo especialización en actividades de rápido crecimiento, sin embargo, se constata que en la misma existen también ramas orientadas a servicios tales como, comercio, transporte y comunicaciones junto a los financieros, las que han adquirido una mayor importancia en el contexto regional, el problema que se vislumbra, es que a nivel local no se opta por aquellas ramas que presentan un mayor crecimiento a nivel de país, como por ejemplo, en construcción.

Lo anterior, es sin duda preocupante, pues, si bien es cierto el efecto estructural en base a la PEA es positivo, su magnitud es muy baja, haciéndose prácticamente nulo en términos de aporte en el total, visto esto, se entiende que la región prácticamente no sólo muestra una estructura inicial especializada en actividades de lento crecimiento, sino que además sus niveles de competitividad locales son inferiores a los que los distintos sectores alcanzan a nivel nacional, por tanto, el conjunto sectorial regional, manifiesta una clara ausencia de dinamismo relativo entre sectores.

De no imponerse pronto acciones que reviertan lo anterior, esto es, el plasmar políticas económicas que faciliten por un lado, una readecuación de las distintas especializaciones regionales, hacia sectores más dinámicos y, por otro, medidas que faciliten el lograr una mayor competitividad sectorial, la región se alejará cada vez más de los niveles de crecimiento y desarrollo trazados por el país.

Si se emplea para el ejercicio anterior la variable PIB regionalizado (figura 1), la situación es muy distinta, pues la región manifiesta ambos efectos positivos, esto es, muestra una condición relativamente privilegiada, pues no sólo posee inicialmente una estructura local caracterizada por realizar actividades altamente especializadas que paralelamente muestran un crecimiento mayor que el registrado para el patrón de referencia, sino que además estas, manifiestan un nivel de competitividad sectorial local, mayor que la que se observa en los mismos sectores a nivel nacional.

Aún cuando lo anterior se presenta como un escenario más favorable que el observado en base a la PEA, se hace notar que, el efecto estructural (1242) sigue siendo muy bajo respecto al diferencial (22167), sin embargo, también se aprecia que la región se está especializando en actividades de rápido crecimiento tales como industria manufacturera y transporte y comunicaciones, actividades que dan fuerza a su vez al efecto competitivo local, lo que favorecería desde el punto de vista de la producción un mayor crecimiento doméstico.

\section{PIB per cápita regional y la tasa de crecimiento} anual del PIB per cápita (1999-2005)

Graficar la relación existente entre el PIB per cápita y las tasas a las que éste varia, es de utilidad pues de allí se desprende la senda de crecimiento que presentan las distintas regiones, esto es, se esboza la mayor o menor equidad interregional frente a un contexto nacional, situación que dependerá de cuán sostenido sea el crecimiento local respecto del nacional, es decir, se visualiza que regiones muestran un mayor acercamiento o distanciamiento respecto al dinamismo nacional. Luego tal ejercicio ayuda 


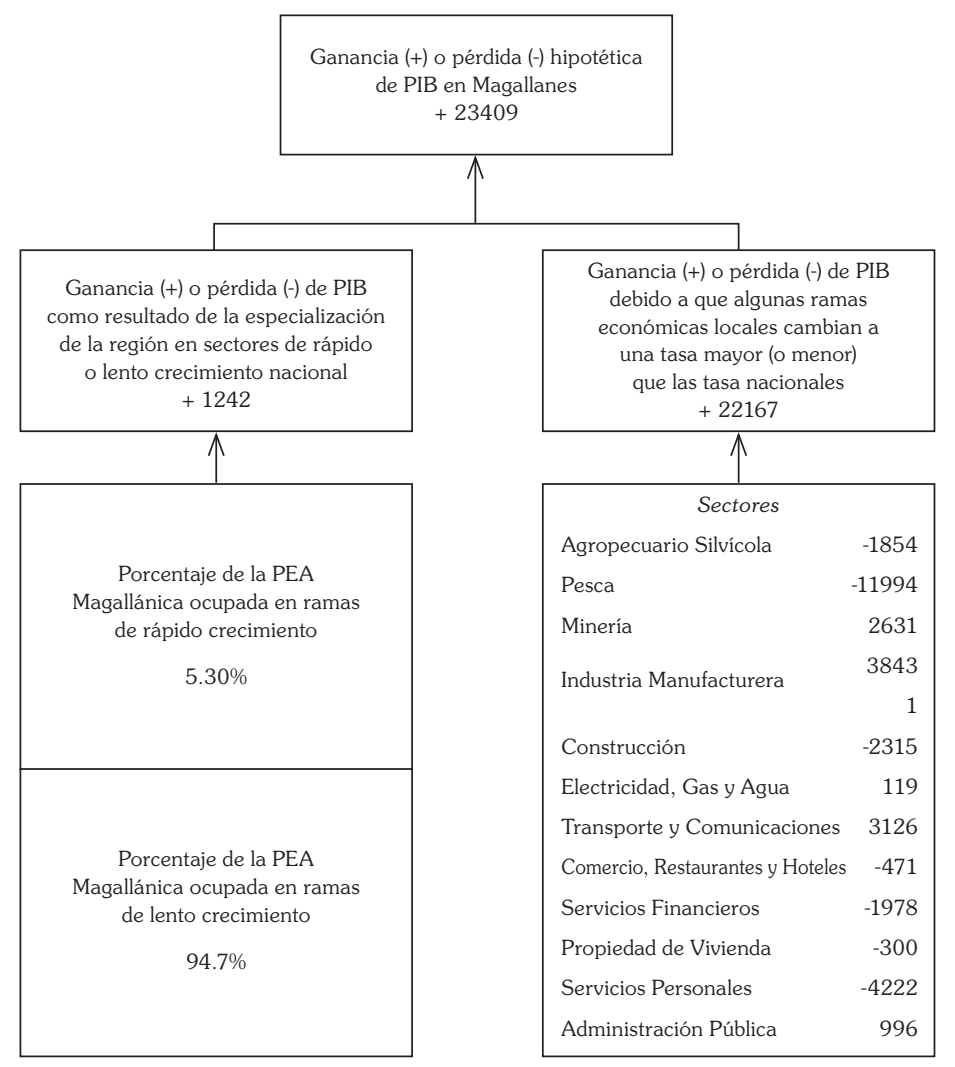

Fig. 6. Análisis diferencial- estructural para Magallanes en base al PIB (2005- 1999).

Fuente: Propia en base a Boisier (1980, pp. 91).

a saber en qué situación se encuentra una región frente al estado que presenta el país en materia de desarrollo, de esta forma, si se observa que una región esta algo rezagada, se hace imperioso hacer que la misma logre una dinámica mayor que este en sintonía con la que muestra el país, a objeto de lograr una cercanía hacia el objetivo trazado.

La forma de analizar lo anterior es a partir de un gráfico en donde, por un lado, se incluyen tales variables (PIB per cápita regional versus la tasa de crecimiento anual que este muestra) y, por otro, que el mismo se divida en cuatro cuadrantes que se leen en el sentido del reloj y, que a su vez quedaran delimitados por la tasa y el valor que alcanza el PIBr per cápita en el último año a nivel nacional. De esta forma, el primer cuadrante indicara que, las regiones que allí se encuentre serán dinámicas y con un alto PIB per cápita, esto es, son regiones que mostraran para el año 1999 un PIB per cápita y una tasa de crecimiento promedio del PIB per cápita para el ciclo 1999- 2005, superiores a las nacionales.
El segundo cuadrante, señalará qué regiones son dinámicas pero con un PIB per cápita bajo, esto es, la tasa del PIB per cápita (1999-2005) es mayor que la que registra el país, sin embargo, su PIB en 1999, era menor que el que presentaba el país.

En el tercer cuadrante, indicará que son regiones con un alto PIB per cápita pero poco dinámicas, esto es, su tasa para el periodo es menor que la del país, pero su PIB durante 1999, era mayor.

Finalmente, el cuarto cuadrante, hará alusión a regiones que presentan un bajo PIB per cápita y además son poco dinámicas, esto es, tanto su PIB per cápita para el año 1999 como su tasa de crecimiento eran menores que la condición nacional.

De acuerdo a la Fig. 7 Magallanes, junto con Aysén, presentarían una situación privilegiada en términos relativos respecto al resto de regiones, al menos durante el período 1999-2005, pues son las únicas regiones que se encuentran en el primer cuadrante. Lo anterior indica que el PIB per cápita que ellas muestran (Magallanes en 1999 y 2005 


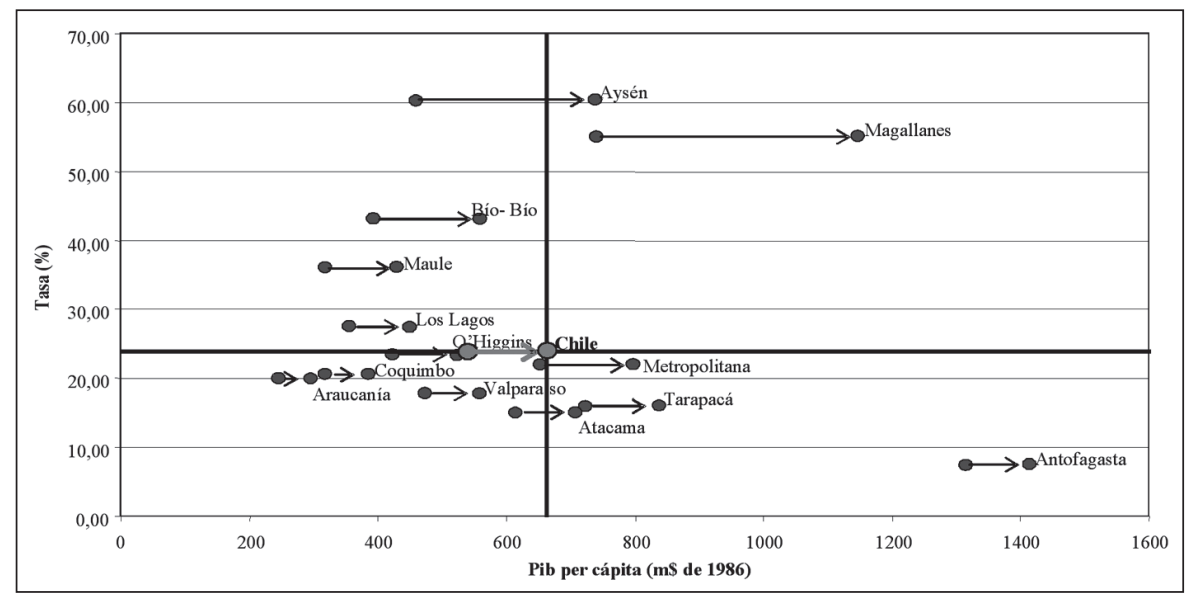

Fig. 7. PIB per cápita regional y la tasa de crecimiento anual del PIB per cápita (1999- 2005). Fuente: Propia

y Aysén sólo en 2005) es superior al del resto del país, de igual forma, tal posicionamiento también refleja que tanto el crecimiento como el nivel de dinamismo logrado en Magallanes durante el periodo 1999- 2005, es superior al que muestra el país, en otras palabras, de mantenerse esa tendencia, cabría esperar para Magallanes un mayor distanciamiento en términos de crecimiento económico y desarrollo respecto a lo que manifiesta el resto del país, es decir, Magallanes, sería una región con tendencias a mostrar mayores niveles de crecimiento y de desarrollo en comparación a lo que ocurre en el resto de las regiones.

Aún cuando lo anterior manifiesta un escenario plausible en términos de desarrollo para la región, hay otros aspectos a tener en consideración que indican que ello es discutible $y$, que tales niveles de crecimiento y desarrollo son menores a lo mostrado. Primero, el alto PIB registrado se debe a la presencia de la producción de metanol, el cual no presenta la misma importancia relativa respecto a las otras actividades realizadas en el resto de regiones, si este se excluye, el escenario es muy distinto. Segundo, la tasa de crecimiento para el empleo registrada en igual periodo en la región, es significativamente baja $(1.19 \%)$ y, sólo es seguida por la región del Bío- Bío (6.27\%), siendo el promedio nacional un $9.26 \%$, y el mayor valor registrado es $16.72 \%$ en la Araucania. Es decir, tal posicionamiento no implica un cambio o liderazgo real en las expectativas económicas, además, se debe considerar que el empleo directo $e$ indirecto que aporta el producción de metanol en la región es bajo, sin incluir el efecto de la conmutatividad regional presente por tal proceso.

\section{NOTAS Y REFLEXIONES FINALES}

Es importante tener presente que si se desea lograr que aumente un sector productivo en una región o provincia dada, se debe hacer a través de la implementación de políticas específicas, y no esperar que el sector se desarrolle, según la dependencia o interrelación que este tenga con las políticas de crecimiento económico nacional (Alburquerque, 1996).

Por otra parte $y$, en referencia a la técnica empleada, se considera una ventaja la secuencia lógica de análisis estructurado que ésta presenta, además de ser fácil de aplicar, lo que permite planificar y tomar decisiones en forma continua y con un mayor grado de certeza, todo ello en la medida que los datos sean fidedignos, detallados y hayan sido bien elaborados. Esto es, entre otros, que no existan errores en la toma de la muestra o en la elaboración de las mismas y que, por otra parte, exista un grado de confianza alto en cuanto al éxito de la proyección que se tenga a futuro.

También es útil considerar la importancia que cobra cada rama o lo concentradas que puedan estar ellas en las distintas regiones, ya que una estructura más diversificada permitirá proyectarse con más facilidad (mayor adaptación al medio), o en las palabras de F. Suarez (1994), entregaría una "mayor flexibilidad". 
Adicionalmente, debe tenerse especial cuidado con el lapso que se tome, y la forma en que se considere la participación de cada sector tanto a nivel regional como nacional, al igual que la proyección de precios que se emplee en la determinación de la estructura económica que se está estudiando.

Un punto que no deja de llamar la atención respecto de los resultados obtenidos, es el que guarda relación con los servicios adicionales que requiere cada sector en cuestión, vale decir, para el caso de Magallanes, en general, se aprecia una importante falta de diversidad económica. Además, la actividad se podría ver muy favorecida si esta toma un derrotero más acorde a la inercia que lleva la economía nacional. De darse estas condiciones, se esperaría a futuro una mayor dinámica económica en Magallanes y un importante aumento en el número de los empleos.

No basta con sólo conocer la dinámica y estructura económica de una zona, región o país, tan importante como esto y quizás más aún es el poder proyectar el efecto de las distintas políticas macroeconómicas en el mercado, o más puntualmente en el sector o en cada empresa en particular, de ello nace la importancia de considerar el efecto de las distintas políticas macroeconómicas en el modelo de desarrollo que se plantee para Magallanes, las cuales a la luz de los resultados, no han tenido un mayor éxito.

Otro aspecto a considerar, es lo poco coincidente que se vuelven las respuestas obtenidas bajo una misma técnica en donde se utilizan distintas variables para medir un mismo fenómeno económico, en este caso la PEA y el PIBr. De acuerdo con la técnica y utilizando la PEA, se puede concluir que la región se identifica actualmente con actividades vinculadas a los servicios (comercio, transporte y comunicaciones y financieros), mientras que en antaño su actividad se basaba en la minería. Sin embargo, en base al PIBr, se observa que la economía Magallánica, se fundamenta en la minería pero, básicamente en la industria manufacturera, esto es, aún cuando la minería es una actividad que históricamente ha perdurado en la región, ella no tiene hoy en día la relevancia que presentaba en los años 60, en este sentido, ella ha sido cambiada en parte por las actividades manufactureras.

Desde otra perspectiva, se observa que Magallanes se especializa, en base a la PEA, en la elaboración de productos con rápido crecimiento a nivel regional, pero no así a nivel nacional. Esto facilitaría que la región se aleje de los distintos efectos de política económicas nacionales, ya que ellos se centran más en el conjunto y no en casos particulares.

Con respecto a la generación de empleo y aumento de la producción, el multiplicador keynesiano para el empleo disminuyo en aproximadamente un $2 \%$ entre 1999 y 2005 y el del PIBr en un 23\%, lo anterior se interpreta como una disminución del impacto que tiene la base económica en la generación de empleos y producción. En el caso del multiplicador de empleo para el año 2005, era de un 9.94 en Magallanes, es decir, por cada puesto de trabajo generado en la base económica que, para este caso la formarían las ramas minería, electricidad, gas y agua, construcción, trasporte y comunicaciones y servicios sociales y comunales, se hubiesen creado hipotéticamente nueve puestos de trabajo adicionales y en el caso del PIBr, la producción hipotéticamente se habría incrementado en 3.13 veces.

En lo referente a la base económica, se aprecia que ella cambia según la variable y año que se considere, sin embargo, se observa una similitud común para los sectores minería y trasporte y comunicaciones, esto es, la región se identifica más para el periodo estudiado con tales actividades, las que se entiende formarían el vertebrado del entrado económico regional para data analizada. Esto último, se presenta como una evidencia de los posibles impactos que se puedan producir en la economía magallánica, pues, desde dos variables distintas se comprueba cuál es el impacto hipotético en, por un lado, la generación de empleo y, por otro, en la producción de las distintas actividades económicas.

Si se considera la variable empleo, la región presenta una estructura similar a la del país, lo cual es una buena señal en términos de política económica, ya que su dinámica obedecerá a la inercia que trae consigo la economía nacional pero, la variable $\mathrm{PIBr}$ indica lo contrario, esto es, que la región obedece a un comportamiento distinto del nacional, lo cual iría en desmedro del crecimiento local que se pueda deber a políticas nacionales, por tanto, es un aspecto a corregir, esto es, tanto la producción regional como su vertebrado y entramado, deben acercarse a la estructura nacional. 


\section{AGRADECIMIENTOS}

El autor desea agradecer los comentarios y sugerencias vertidos por los árbitros anónimos y editores de esta revista. De igual modo, desea hacer presente su reconocimiento a la Sra. Mábel Arratia Fuentes (Universidad de Magallanes). Cualquier error u omisión es responsabilidad del infrascrito, no comprometiendo por tanto a los anteriores, o a esta revista, ni al Grupo ICM, o a la Universidad de Magallanes.

\section{BIBLIOGRAFÍA}

ALBURQUERQUE, F. 1996. Desarrollo económico local y distribución del progreso técnico: una respuesta a las exigencias del ajuste estructural. Instituto Latinoamericano y del Caribe de Planificación Económica y Social, ILPES, Santiago, Chile.

BOISIER, S. 1980. Técnicas de análisis regional con información limitada. Instituto Latinoamericano y del Caribe de Planificación Económica y Social, ILPES, Santiago, Chile.

DINC, M.; HAYNES, K. E. AND QIANGSHENG, L. 1998. A comparative evaluation of shift-share models and their extensions. Australian Journal of Regional Studies. $4(2): 275-302$.

FERNÁNDEZ, A., GONZÁLES, P., REGÚlEZ, M., MORAL, M. P., ESTEBAN, M. V. 1995. Ejercicios de econometría. España: Mc Graw Hill.

FINGLETON, B. 2001. Equilibrium and Economic Growth: Spatial Econometric Models and Simulations. Journal of Regional Science. 41(1):117-147.

GUJARATI, D. 1992. Econometría. Mc Graw Hill, México.

GEARY, R. 1954. The contiguity ratio and statistical mapping. The Incorporated Statistican. 5: 115- 145.

HAX, A., Y N. MAJLUF. 1993. Gestión de empresa con una visión estratégica. Ediciones Dolmen, Chile.

HADDAD, P; CARVALHO FERREIRA, C. Y OTROS. 1989. Economia regional: teorias e métodos de analise. Banco do Nordeste do Brasil. Fortaleza.

HEWINGS, G.J.D. 1976. On the accuracy of alternative models for stepping-down multi-county employment proyections to countries. Economic Geography. 52: 206-217.

LAMBIN, J. 1991. Marketing estratégico. McGraw Hill, Madrid.

LARROULET, C., MOCHÓN, F. 1995. Economía. Mc Graw Hill, Chile.

LIRA, L. 1997. Información y conocimiento para el análisis regional conducente a la toma de decisiones. Instituto
Latinoamericano y 1del Caribe de Planificación Económica y Social, ILPES, Santiago, Chile.

LIRA, L., Y V. SILVA. 1993. Técnicas de análisis regional: ejercitación y aplicación. Instituto Latinoamericano y del Caribe de Planificación Económica y Social, ILPES, Santiago, Chile.

NAZARA, S. AND HEWINGS, G.J.D. 2004. Spatial structure and taxonomy of Decompotition in shift-share analysis. Growth and Change 35(4): 476-490.

NOURSE, H. 1968. Economía regional: medida de la actividad económica regional: OIKOS- TAU.

MADALA, G., MILLER, E. 1989. Microeconomía. Mc Graw Hill, México.

MAYOR, M. Y A. J. LÓPEZ. 2005a. Nuevos desarrollos del análisis shift-share espacial. Una aplicación al empleo comarcal de Asturias. En: XIX Reunión ASEPELT-España, Facultad de Ciencias Económicas y Empresariales, Universidad de Badajoz, Badajoz, España, 8-11 de junio. 2005b. El Análisis Shift-Share Espacial: Nuevos desarrollos. En: VIII Encuentro de Economía Aplicada- España, Facultad de Economía y Empresas, Universidad de Murcia, España, 16- 18 de junio.

MIDEPLAN. 1994. Métodos y técnicas de planificación regional. Ministerio de Planificación y Cooperación. Alfabeta Impresores, Chile.

1998. Evolución de la actividad económica regional 1985- 1996: análisis del Producto Interno Bruto desde un enfoque nacional/regional. Ministerio de Planificación y Cooperación. Chile: Andros Impresores.

MORAN, P. 1948. The interpretation of statistical maps. Journal of the Royal Statistical Society B. 10: 641- 658.

PORTER, M. 1991. Estrategia Competitiva: técnicas para el análisis de sectores industriales y de la competencia. CECSA, México.

SACHS, J., LARRAÍN, F. 1994. Macroeconomía en la economía global. Prentice Hall Hispanoamericana, México.

SAPAG, N., SAPAG, R. 1991. Preparación y evaluación de proyectos. Mc Graw Hill, Chile.

SOZA, S. 2000. Propuesta Metodológica para lograr una Planificación Estratégica en Regiones: Optimizando Herramientas, NEXOS, Facultad de Ciencias Económicas y Administrativas, Universidad Austral de Chile, Valdivia, Chile.

SUÁREZ, F. 1994. La competitividad de las empresas: evolución, imperativos estratégicos y características de la organización exitosa de hoy. Estudios Públicos, 54: 152-175.

TIEBOUT, C. 1972. Valoración de los modelos input- output regionales e intrarregionales. En: Análisis Regional, Needleman (comp.) Universidad de Navarra, España. 
ANEXOS:

Tabla 1: Participación del Sector en la Región para la PEA en 2005 (en tanto por uno)

A- S- C y P
Minas
Industria
E-G-A
Construcción
Comercio
T y C
Ss. Financieros
Ss. CC. Y SS

Reg 1 Reg 2 Reg 3 Reg 4 Reg 5 Reg 6 Reg 7 Reg 8 Reg 9 Reg 10 Reg 11 Reg 12 RM SEC

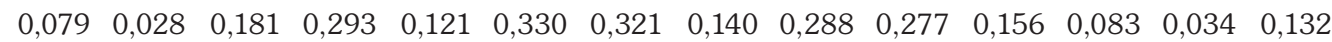
$\begin{array}{llllllllllllll}0,020 & 0,120 & 0,092 & 0,043 & 0,017 & 0,021 & 0,005 & 0,005 & 0,000 & 0,000 & 0,013 & 0,048 & 0,002 & 0,013\end{array}$ $\begin{array}{llllllllllllll}0,106 & 0,079 & 0,069 & 0,067 & 0,089 & 0,093 & 0,110 & 0,161 & 0,108 & 0,153 & 0,103 & 0,104 & 0,155 & 0,131\end{array}$ $\begin{array}{llllllllllllll}0,013 & 0,011 & 0,006 & 0,005 & 0,008 & 0,011 & 0,006 & 0,003 & 0,005 & 0,004 & 0,019 & 0,006 & 0,005 & 0,006\end{array}$ $\begin{array}{llllllllllllll}0,058 & 0,173 & 0,134 & 0,101 & 0,069 & 0,088 & 0,070 & 0,066 & 0,064 & 0,057 & 0,073 & 0,085 & 0,083 & 0,080\end{array}$ $\begin{array}{llllllllllllll}0,247 & 0,168 & 0,179 & 0,179 & 0,189 & 0,159 & 0,154 & 0,171 & 0,159 & 0,146 & 0,147 & 0,182 & 0,212 & 0,189\end{array}$ $\begin{array}{llllllllllllll}0,125 & 0,099 & 0,060 & 0,064 & 0,088 & 0,055 & 0,066 & 0,081 & 0,064 & 0,075 & 0,093 & 0,118 & 0,082 & 0,080\end{array}$ $\begin{array}{llllllllllllll}0,080 & 0,073 & 0,047 & 0,038 & 0,065 & 0,051 & 0,045 & 0,061 & 0,048 & 0,040 & 0,047 & 0,071 & 0,133 & 0,088\end{array}$

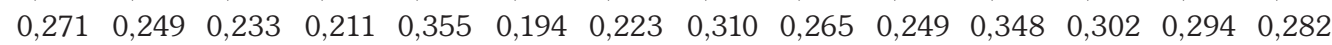

Fuente: Propia.

Tabla 2: Participación de la Región en el Sector según PEA para 2005 (en tanto por uno).

A- S- C y P

Minas

Industria

E-G-A

Construcción

Comercio

Ty $\mathrm{C}$

Ss. Financieros

Ss. CC. Y SS

Reg 1 Reg 2 Reg 3 Reg 4 Reg 5 Reg 6 Reg 7 Reg 8 Reg 9 Reg 10 Reg 11 Reg 12 RM

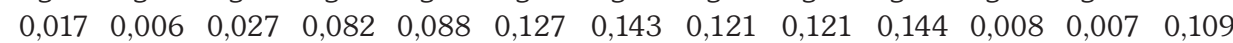
$\begin{array}{lllllllllllll}0,044 & 0,278 & 0,144 & 0,126 & 0,129 & 0,085 & 0,024 & 0,047 & 0,000 & 0,002 & 0,007 & 0,042 & 0,072\end{array}$ $\begin{array}{lllllllllllll}0,022 & 0,018 & 0,010 & 0,019 & 0,065 & 0,036 & 0,049 & 0,138 & 0,045 & 0,080 & 0,005 & 0,009 & 0,503\end{array}$ $\begin{array}{lllllllllllll}0,060 & 0,056 & 0,019 & 0,032 & 0,134 & 0,095 & 0,056 & 0,066 & 0,047 & 0,045 & 0,023 & 0,012 & 0,355\end{array}$ $\begin{array}{lllllllllllll}0,020 & 0,064 & 0,033 & 0,047 & 0,083 & 0,056 & 0,051 & 0,094 & 0,044 & 0,049 & 0,006 & 0,012 & 0,440\end{array}$ $\begin{array}{lllllllllllll}0,036 & 0,026 & 0,019 & 0,035 & 0,097 & 0,043 & 0,048 & 0,103 & 0,046 & 0,053 & 0,005 & 0,011 & 0,479\end{array}$ $\begin{array}{lllllllllllll}0,043 & 0,036 & 0,015 & 0,030 & 0,107 & 0,035 & 0,048 & 0,115 & 0,044 & 0,064 & 0,008 & 0,016 & 0,439\end{array}$ $\begin{array}{lllllllllllll}0,025 & 0,024 & 0,011 & 0,016 & 0,071 & 0,029 & 0,029 & 0,078 & 0,030 & 0,031 & 0,004 & 0,009 & 0,643\end{array}$ $\begin{array}{lllllllllllll}0,026 & 0,026 & 0,016 & 0,028 & 0,122 & 0,035 & 0,046 & 0,124 & 0,052 & 0,060 & 0,009 & 0,012 & 0,444\end{array}$

Fuente: Propia.

Tabla 3: Cociente de Localización (Qij).

Reg 1 Reg 2 Reg 3 Reg 4 Reg 5 Reg 6 Reg 7 Reg 8 Reg 9 Reg 10 Reg 11 Reg 12 RM

A- S- C y P

Minas

Industria

E-G-A

Construcción

Comercio

Ty C

S. Financieros

S. CC. Y SS $\begin{array}{lllllllllllll}0,604 & 0,212 & 1,372 & 2,225 & 0,916 & 2,505 & 2,441 & 1,067 & 2,185 & 2,102 & 1,188 & 0,628 & 0,256 \\ 1,589 & 9,517 & 7,286 & 3,395 & 1,334 & 1,669 & 0,405 & 0,420 & 0,000 & 0,028 & 0,999 & 3,837 & 0,170 \\ 0,808 & 0,603 & 0,528 & 0,508 & 0,675 & 0,705 & 0,840 & 1,225 & 0,823 & 1,169 & 0,785 & 0,789 & 1,180 \\ 2,164 & 1,926 & 0,960 & 0,869 & 1,387 & 1,861 & 0,955 & 0,580 & 0,860 & 0,666 & 3,287 & 1,081 & 0,834 \\ 0,733 & 2,171 & 1,679 & 1,271 & 0,864 & 1,099 & 0,879 & 0,832 & 0,800 & 0,713 & 0,912 & 1,066 & 1,034 \\ 1,306 & 0,891 & 0,948 & 0,947 & 0,999 & 0,840 & 0,818 & 0,908 & 0,841 & 0,772 & 0,779 & 0,965 & 1,125 \\ 1,571 & 1,236 & 0,752 & 0,797 & 1,105 & 0,687 & 0,827 & 1,016 & 0,806 & 0,933 & 1,170 & 1,484 & 1,030 \\ 0,904 & 0,824 & 0,537 & 0,429 & 0,737 & 0,579 & 0,505 & 0,691 & 0,543 & 0,455 & 0,535 & 0,804 & 1,508 \\ 0,963 & 0,882 & 0,825 & 0,748 & 1,259 & 0,687 & 0,789 & 1,100 & 0,938 & 0,881 & 1,235 & 1,072 & 1,043\end{array}$

Fuente: Propia.

7 Con el objeto de facilitar la construcción de las tablas se toma la nomenclatura antigua de las regiones chilenas así: Reg1= Atacama; Reg2= Antofagasta; Reg3= Tarapacá; Reg4= Coquimbo; Reg5= Valparaíso; Reg6= O'Higgins; Reg7= Maule; Reg8= Bío- Bío; Reg9= Araucanía; Reg10= Los lagos; Reg11= Aysén; Reg12= Magallanes y R.M.= Región Metropolitana 
Tabla 4: Coeficiente de Especialización (matriz de diferencias).

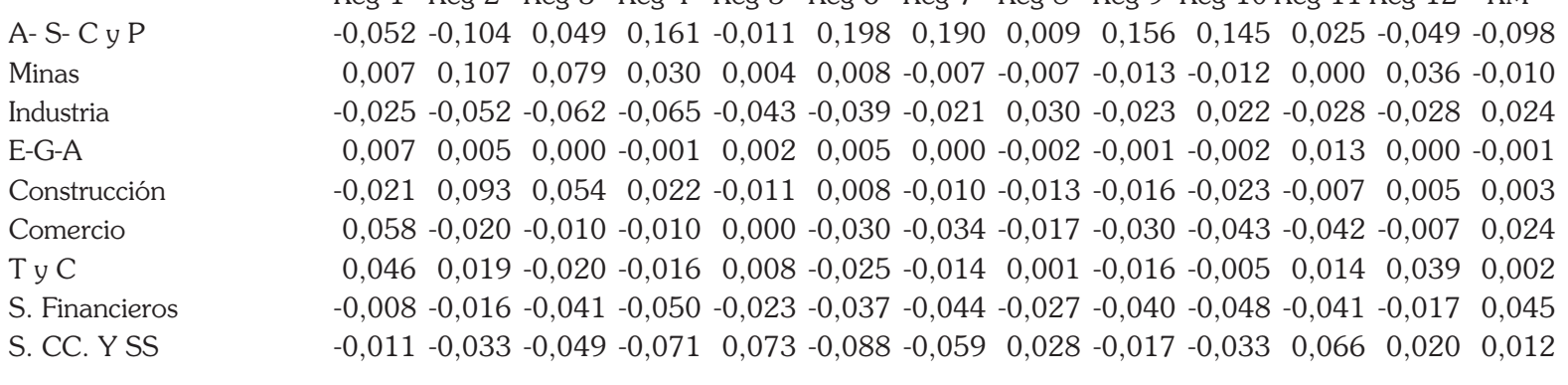

Fuente: Propia.

Tabla 5: Coeficiente de Especialización (vector; $\mathrm{Q}^{\wedge} \mathrm{r}$ ).

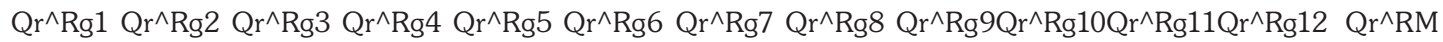

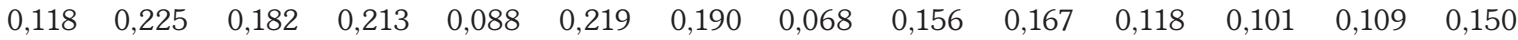
Fuente: Propia.

Tabla 6: Base Económica para el año 2005.

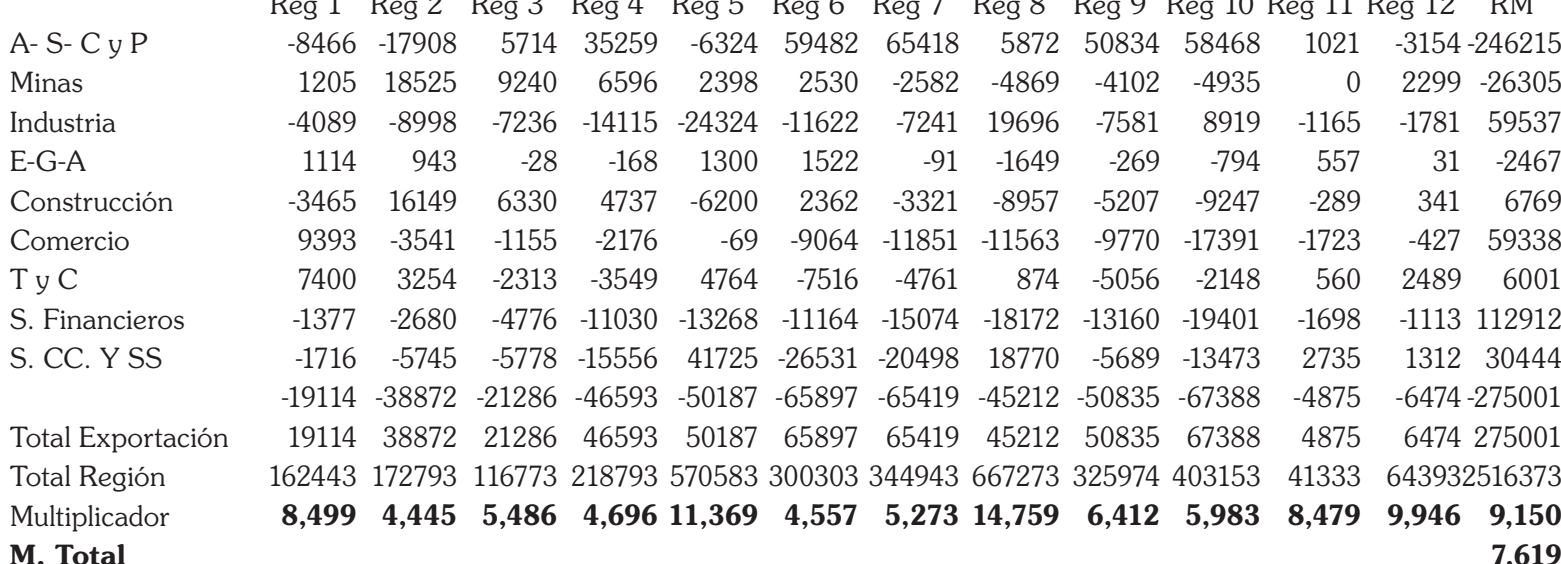

Fuente: Propia.

Tabla 7: Coeficiente de Localización (matriz); 2005.

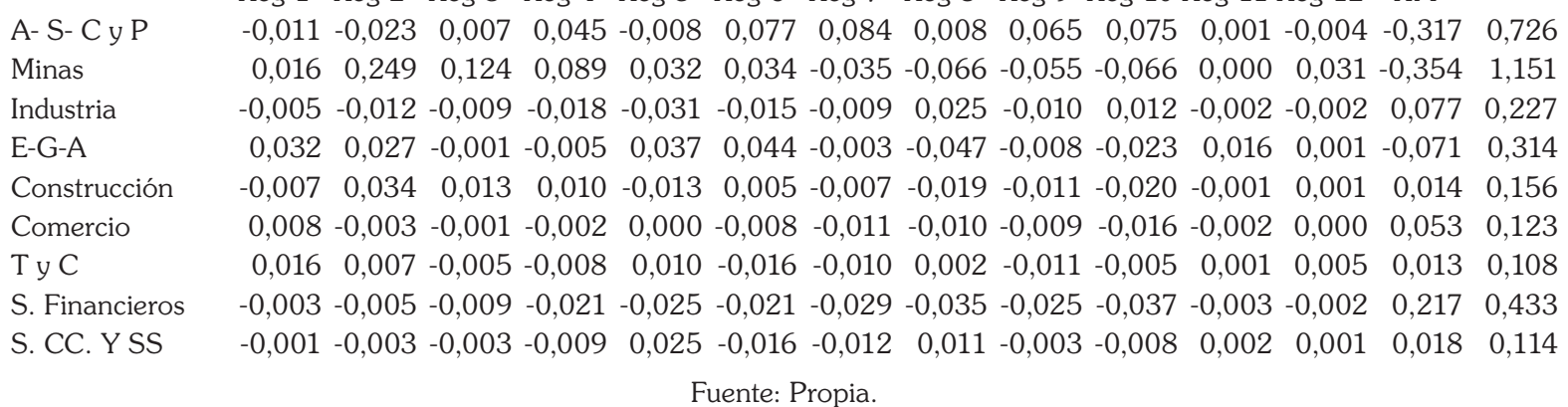


Tabla 8: Coeficiente de Localización (vector; $\mathrm{Q}^{\wedge} \mathrm{Sn}$ ); 2005.

$\begin{array}{llr} & \mathrm{Q} s \wedge \mathrm{n}=(\mathrm{ABS}(\text { Suma } & \mathrm{SEC})) / 2 \\ \text { A- S- C y P } & \mathrm{Qs} \wedge 1 & 0,363 \\ \text { Minas } & \mathrm{Qs} \wedge 2 & 0,576 \\ \text { Industria } & \mathrm{Qs} \wedge 3 & 0,114 \\ \text { E-G-A } & \mathrm{Qs} \wedge 4 & 0,157 \\ \text { Construcción } & \mathrm{Qs} \wedge 5 & 0,078 \\ \text { Comercio } & \mathrm{Qs} \wedge 6 & 0,062 \\ \text { T y C } & \mathrm{Qs} \wedge 7 & 0,054 \\ \text { S. Financieros } & \mathrm{Qs} \wedge 8 & 0,217 \\ \text { S. CC. Y SS } & \mathrm{Qs} \wedge 9 & 0,057\end{array}$

Fuente: Propia.

Tabla 9: Cuociente de variación 2005-1999.

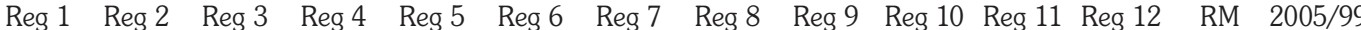
$\begin{array}{llllllllllllllll}\text { Minas } & & 1,7473 & 1,1159 & 1,0009 & 1,2791 & 1,2157 & 0,7987 & 1,5304 & 1,0292 & 0,0026 & 0,1944 & 1,0196 & 0,8988 & 0,5683 & 1,0139\end{array}$ $\begin{array}{lllllllllllllll}\text { Industria } & 1,1525 & 0,9892 & 0,8106 & 0,9561 & 1,0875 & 0,9236 & 0,9702 & 1,0411 & 1,3354 & 1,3192 & 0,9884 & 0,7330 & 0,9370 & 0,9994\end{array}$ $\begin{array}{llllllllllllllll}\text { E-G-A } & 0,8554 & 1,4307 & 0,8049 & 1,4737 & 0,8351 & 4,3289 & 1,5397 & 1,1875 & 2,7966 & 2,2899 & 6,6667 & 0,7321 & 1,0628 & 1,2213\end{array}$ $\begin{array}{lllllllllllllll}\text { Construcción } & 0,8821 & 1,4450 & 1,4667 & 1,0259 & 1,2332 & 2,0831 & 1,0155 & 0,8441 & 1,4801 & 1,1826 & 0,8958 & 0,8882 & 1,2895 & 1,2127\end{array}$ $\begin{array}{lllllllllllllll}\text { Comercio } & 1,0734 & 1,0360 & 1,0972 & 1,1174 & 1,0455 & 1,1703 & 0,9762 & 1,0504 & 1,2751 & 1,1801 & 1,4686 & 1,2820 & 1,0753 & 1,0853\end{array}$ $\begin{array}{llllllllllllllll}\text { Tу C } & 1,2011 & 1,1428 & 0,9818 & 1,0969 & 0,9132 & 1,1107 & 1,2340 & 1,1357 & 1,6281 & 1,1264 & 1,3310 & 1,2738 & 1,2387 & 1,1692\end{array}$

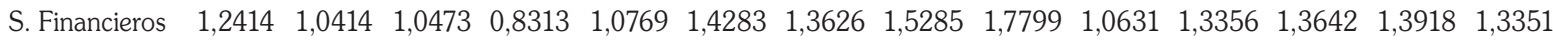
$\begin{array}{lllllllllllllll}\text { S. CC. Y SS } & 1,2274 & 1,1929 & 1,1820 & 1,2572 & 1,1390 & 1,0393 & 1,1910 & 1,1936 & 1,0220 & 1,0069 & 1,2299 & 1,0384 & 1,0277 & 1,0829\end{array}$ $\begin{array}{lllllllllllllll}1,1402 & 1,1379 & 1,1433 & 1,1184 & 1,0785 & 1,0840 & 1,0724 & 1,0627 & 1,1672 & 1,0865 & 1,1101 & 1,0119 & 1,0914 & 1,0926\end{array}$

Fuente: Propia.

Tabla 10: Coeficiente de reestructuración (matriz; CR^R); 2005-1999.

$\begin{array}{llllllllllll}\text { Reg } 1 & \text { Reg } 2 & \text { Reg } 3 & \text { Reg } 4 & \text { Reg } 5 & \text { Reg } 6 & \text { Reg } 7 & \text { Reg } 8 & \text { Reg } 9 & \text { Reg } 10 & \text { Reg } 11 & \text { Reg } 12 \\ \text { RM }\end{array}$ $\begin{array}{lllllllllllllllll}\text { A- S- C y P } & -0,0036 & -0,0135 & 0,0285 & 0,0051 & -0,0057 & -0,0437 & -0,0127 & -0,0355 & -0,0392 & -0,0258 & -0,0782 & -0,0290 & -0,0022\end{array}$ $\begin{array}{llllllllllllll}\text { Minas } & 0,0070 & -0,0024 & -0,0130 & 0,0054 & 0,0019 & -0,0075 & 0,0015 & -0,0002 & -0,0014 & -0,0016 & -0,0011 & -0,0061 & -0,0020\end{array}$ $\begin{array}{llllllllllllll}\text { Industria } & 0,0011 & -0,0119 & -0,0284 & -0,0113 & 0,0007 & -0,0161 & -0,0116 & -0,0033 & 0,0136 & 0,0271 & -0,0127 & -0,0394 & -0,0255\end{array}$ $\begin{array}{llllllllllllll}\text { E-G-A } & -0,0042 & 0,0023 & -0,0024 & 0,0012 & -0,0024 & 0,0082 & 0,0017 & 0,0004 & 0,0029 & 0,0021 & 0,0161 & -0,0024 & -0,0001\end{array}$

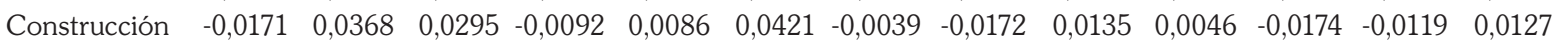
$\begin{array}{llllllllllllll}\text { Comercio } & -0,0153 & -0,0166 & -0,0075 & -0,0002 & -0,0060 & 0,0117 & -0,0152 & -0,0020 & 0,0134 & 0,0116 & 0,0359 & 0,0384 & -0,0032\end{array}$

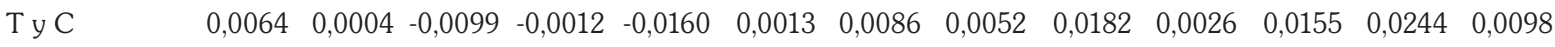

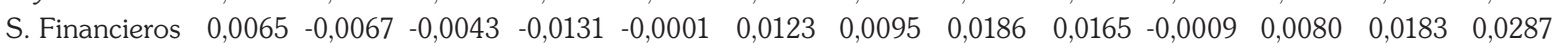

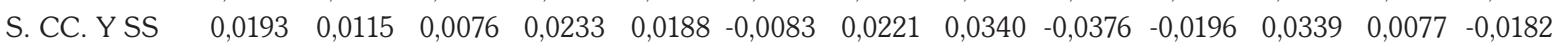
Fuente: Propia.

Tabla 11: Coeficiente de reestructuración (vector; $\left.\mathrm{CR}^{\wedge} \mathrm{R}\right) ; 2005-1999$.

Reg 1 Reg 2 Reg 3 Reg 4 Reg 5 Reg 6 Reg 7 Reg 8 Reg 9 Reg 10 Reg 11 Reg 12 RM Coeficiente $\begin{array}{lllllllllllllllll}0,0403 & 0,0510 & 0,0656 & 0,0350 & 0,0301 & 0,0756 & 0,0435 & 0,0582 & 0,0782 & 0,0479 & 0,1094 & 0,0888 & 0,0512\end{array}$ 
Tabla 12: Efecto Diferencial.

Efecto Diferencial Efecto Estructural Efecto Total

\begin{tabular}{lrrrrrrrrrrrrrr} 
& Reg 1 & Reg 2 & Reg 3 & Reg 4 & Reg 5 & Reg 6 & Reg 7 & Reg 8 & Reg 9 & Reg 10 & Reg 11 & Reg 12 & RM \\
A- S- C y P & 1125 & -1436 & 5610 & 7996 & 2237 & -4022 & 3803 & -16325 & 2821 & -278 & -2236 & -1753 & 2458 \\
Minas & 1364 & 1892 & -139 & 1938 & 1590 & -1700 & 594 & 52 & -394 & -590 & 3 & -398 & -4212 \\
Industria & 2289 & -141 & -1884 & -661 & 4099 & -2281 & -1146 & 4294 & 8856 & 14989 & -47 & -2424 & -25943 \\
E-G-A & -886 & 287 & -341 & 192 & -2155 & 2362 & 401 & -65 & 929 & 737 & 653 & -274 & -1841 \\
Construcción & -3561 & 4813 & 2710 & -4043 & 654 & 11001 & -4701 & -19343 & 3759 & -585 & -1065 & -2002 & 12363 \\
Comercio & -443 & -1384 & 226 & 1124 & -4101 & 3459 & -5954 & -3799 & 7708 & 4717 & 1587 & 1800 & -4940 \\
T y C & 541 & -394 & -1338 & -917 & -14102 & -867 & 1197 & -1596 & 5911 & -1142 & 469 & 627 & 11611 \\
S. Financieros & -979 & -3545 & -1520 & -5018 & -8892 & 1001 & 310 & 5152 & 3901 & -4141 & 1 & 97 & 13633 \\
S. CC. Y SS & 5193 & 3964 & 2276 & 6399 & 9978 & -2437 & 6968 & 19204 & -5132 & -7557 & 1720 & -834 & -39743 \\
Diferencial & 4645 & 4055 & 5601 & 7010 & -10692 & 6516 & 1473 & -12427 & 28359 & 6150 & 1085 & -5162 & -36614 \\
& & & \multicolumn{8}{c}{ Fuente: Propia. }
\end{tabular}

Tabla 13: Efecto Diferencia, Estructural y Total.

Reg 1 Reg 2 Reg 3 Reg 4 Reg 5 Reg 6 Reg 7 Reg 8 Reg 9 Reg 10 Reg 11 Reg 12 RM

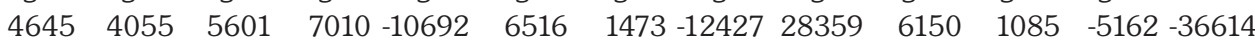
$\begin{array}{lllllllllllll}2129 & 2820 & -421 & -1959 & 3231 & -8894 & -7964 & -6361 & -7536 & -8440 & -434 & 28 & 33801\end{array}$ $\begin{array}{lllllllllllll}6774 & 6875 & 5180 & 5051 & -7461 & -2378 & -6491 & -18788 & 20823 & -2290 & 651 & -5134 & -2813\end{array}$

Fuente: Propia.

Tabla 14: Coeficiente de redistribución (matriz).

A- S- C y P
Minas
Industria
E-G-A
Construcción
Comercio
Ty C
S. Financieros
S. CC. Y SS

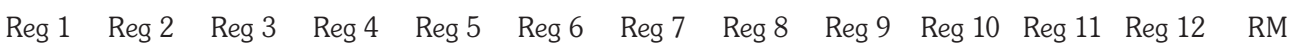

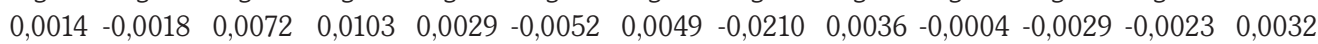
$\begin{array}{lllllllllllll}0,0184 & 0,0254 & -0,0019 & 0,0261 & 0,0214 & -0,0229 & 0,0080 & 0,0007 & -0,0053 & -0,0079 & 0,0000 & -0,0054 & -0,0567\end{array}$ $\begin{array}{lllllllllllll}0,0030 & -0,0002 & -0,0024 & -0,0009 & 0,0053 & -0,0029 & -0,0015 & 0,0055 & 0,0114 & 0,0193 & -0,0001 & -0,0031 & -0,0335\end{array}$ $\begin{array}{lllllllllllll}-0,026 & 0,0082 & -0,0098 & 0,0055 & -0,0620 & 0,0679 & 0,0115 & -0,0019 & 0,0267 & 0,0212 & 0,0188 & -0,0079 & -0,0530\end{array}$ $\begin{array}{llllllllllllll}-0,008 & 0,0102 & 0,0058 & -0,0086 & 0,0014 & 0,0233 & -0,0100 & -0,0410 & 0,0080 & -0,0012 & -0,0023 & -0,0042 & 0,0262\end{array}$ $\begin{array}{llllllllllllll}-0,000 & -0,0012 & 0,0002 & 0,0010 & -0,0037 & 0,0031 & -0,0053 & -0,0034 & 0,0069 & 0,0042 & 0,0014 & 0,0016 & -0,0044\end{array}$ $\begin{array}{lllllllllllll}0,0011 & -0,0008 & -0,0028 & -0,0019 & -0,0299 & -0,0018 & 0,0025 & -0,0034 & 0,0125 & -0,0024 & 0,0010 & 0,0013 & 0,0246\end{array}$ $\begin{array}{lllllllllllll}-0,002 & -0,0068 & -0,0029 & -0,0096 & -0,0171 & 0,0019 & 0,0006 & 0,0099 & 0,0075 & -0,0079 & 0,0000 & 0,0002 & 0,0262\end{array}$ $\begin{array}{llllllllllllll}0,0031 & 0,0024 & 0,0014 & 0,0038 & 0,0060 & -0,0015 & 0,0042 & 0,0115 & -0,0031 & -0,0045 & 0,0010 & -0,0005 & -0,0239\end{array}$

\section{Fuente: Propia.}

Tabla 15: Coeficiente de redistribución (vector).

$\begin{array}{ll}\text { A- S- C y P } & 0,0335 \\ \text { Minas } & 0,1000 \\ \text { Industria } & 0,0446 \\ \text { E-G-A } & 0,1600 \\ \text { Construcción } & 0,0749 \\ \text { Comercio } & 0,0185 \\ \text { T y C } & 0,0432 \\ \text { S. Financieros } & 0,0462 \\ \text { S. CC. Y SS } & 0,0335\end{array}$

Fuente: Propia. 